NASA/TM-2010-216685

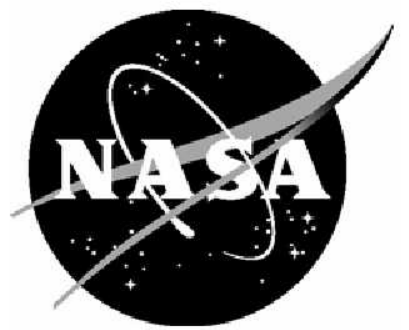

\title{
Human Response to Low-Intensity Sonic Booms Heard Indoors and Outdoors
}

Brenda M. Sullivan

Lockheed Martin, Hampton, Virginia

Jacob Klos, Ralph D. Buehrle, and David A. McCurdy

Langley Research Center, Hampton, Virginia

Edward A. Haering, Jr.

Dryden Flight Research Center, Edwards, California 


\section{NASA STI Program ... in Profile}

Since its founding, NASA has been dedicated to the advancement of aeronautics and space science. The NASA scientific and technical information (STI) program plays a key part in helping NASA maintain this important role.

The NASA STI program operates under the auspices of the Agency Chief Information Officer. It collects, organizes, provides for archiving, and disseminates NASA's STI. The NASA STI program provides access to the NASA Aeronautics and Space Database and its public interface, the NASA Technical Report Server, thus providing one of the largest collections of aeronautical and space science STI in the world. Results are published in both non-NASA channels and by NASA in the NASA STI Report Series, which includes the following report types:

- TECHNICAL PUBLICATION. Reports of completed research or a major significant phase of research that present the results of NASA programs and include extensive data or theoretical analysis. Includes compilations of significant scientific and technical data and information deemed to be of continuing reference value. NASA counterpart of peerreviewed formal professional papers, but having less stringent limitations on manuscript length and extent of graphic presentations.

- TECHNICAL MEMORANDUM. Scientific and technical findings that are preliminary or of specialized interest, e.g., quick release reports, working papers, and bibliographies that contain minimal annotation. Does not contain extensive analysis.

- CONTRACTOR REPORT. Scientific and technical findings by NASA-sponsored contractors and grantees.
- CONFERENCE PUBLICATION. Collected papers from scientific and technical conferences, symposia, seminars, or other meetings sponsored or co-sponsored by NASA.

- SPECIAL PUBLICATION. Scientific, technical, or historical information from NASA programs, projects, and missions, often concerned with subjects having substantial public interest.

- TECHNICAL TRANSLATION. Englishlanguage translations of foreign scientific and technical material pertinent to NASA's mission.

Specialized services also include creating custom thesauri, building customized databases, and organizing and publishing research results.

For more information about the NASA STI program, see the following:

- Access the NASA STI program home page at http://www.sti.nasa.gov

- E-mail your question via the Internet to help@sti.nasa.gov

- Fax your question to the NASA STI Help Desk at $443-757-5803$

- Phone the NASA STI Help Desk at 443-757-5802

- Write to:

NASA STI Help Desk NASA Center for AeroSpace Information 7115 Standard Drive Hanover, MD 21076-1320 
NASA/TM-2010-216685

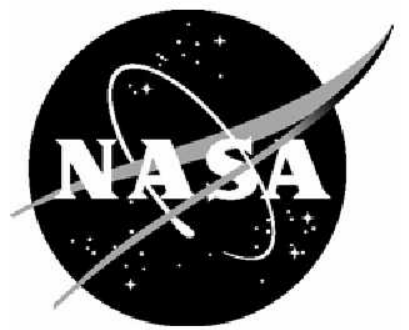

\section{Human Response to Low-Intensity Sonic Booms Heard Indoors and Outdoors}

Brenda M. Sullivan

Lockheed Martin, Hampton, Virginia

Jacob Klos, Ralph D. Buehrle, and David A. McCurdy

Langley Research Center, Hampton, Virginia

Edward A. Haering, Jr.

Dryden Flight Research Center, Edwards, California

National Aeronautics and

Space Administration

Langley Research Center

Hampton, Virginia 23681-2199 


\section{Acknowledgments}

The authors would like to acknowledge the invaluable help provided by the U.S. Air

Force. In particular, the following:

Base Housing Staff

Connie Keeling, James Hart, and Charlotte Meyers (Edwards Housing Office)

Larry Hagenauer

Contr $95 \mathrm{ABW} / \mathrm{CEV}$, Airspace/Flight Operations Analysis, TYBRIN Corporation

Edwards AFB Security Office and Staff

Aero Institute

Tanya Duke and staff (monitors, Katrina Emery, Deborah Barnes, and Raymond Bellem)

Dryden Flight Research Center Operations

Dr. Gregg Bendrick and Craig Bomben

Dryden Office of Academic Investments

Susan B. Miller

The use of trademarks or names of manufacturers in this report is for accurate reporting and does not constitute an official endorsement, either expressed or implied, of such products or manufacturers by the National Aeronautics and Space Administration.

Available from:

NASA Center for AeroSpace Information

7115 Standard Drive

Hanover, MD 21076-1320

443-757-5802 


\section{Contents}

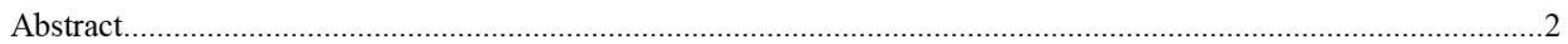

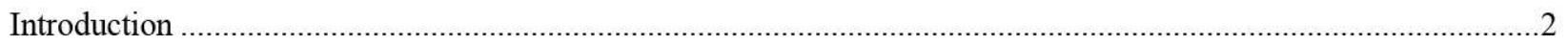

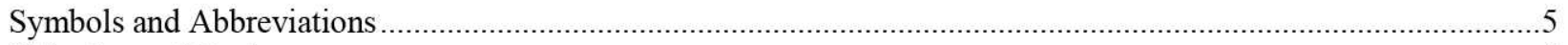

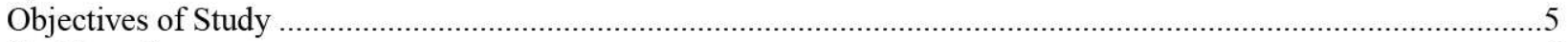

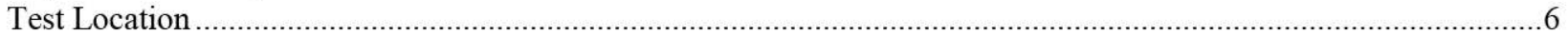

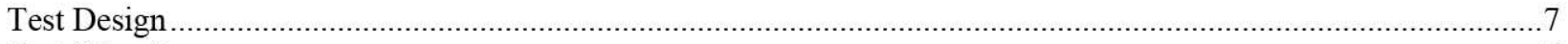

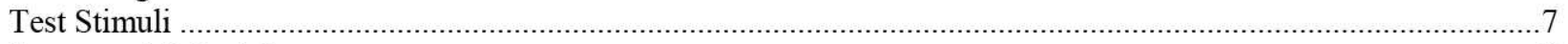

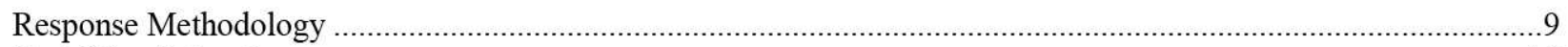

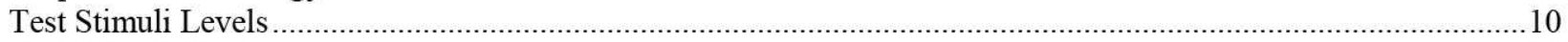

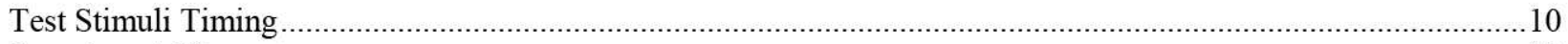

Experimental Layout

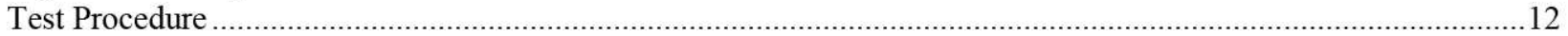

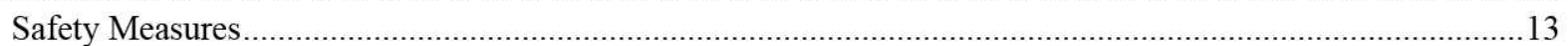

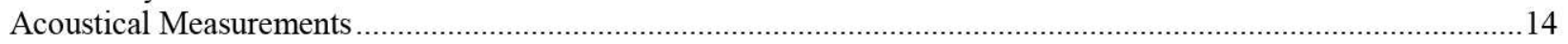

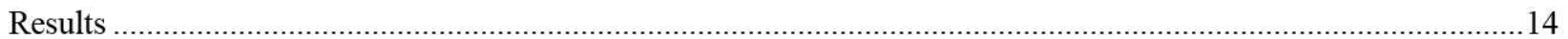

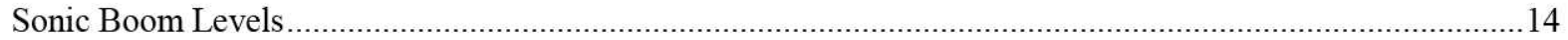

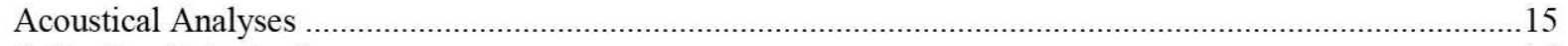

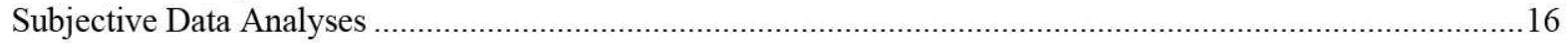

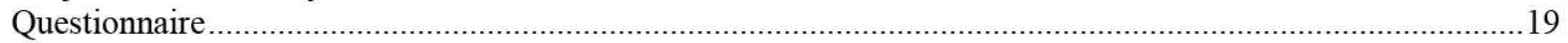

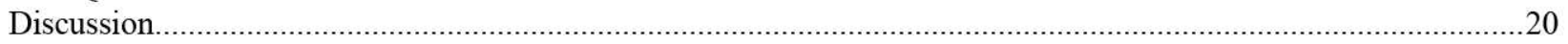

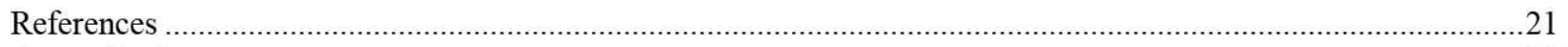

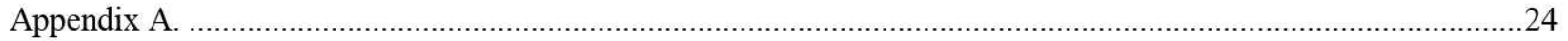

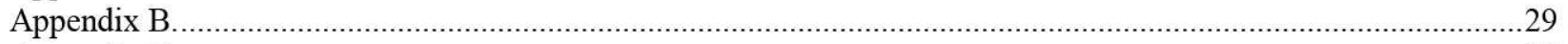

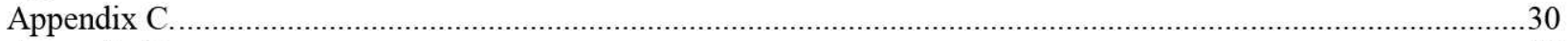

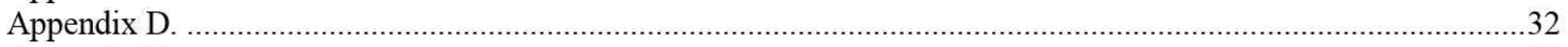

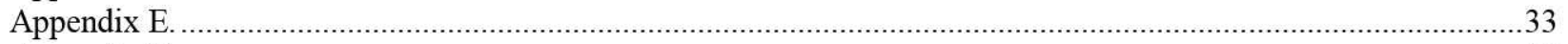

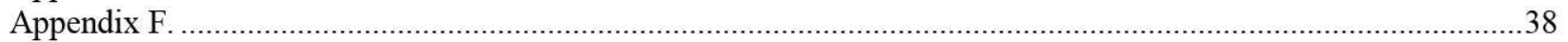




\section{Abstract}

Test subjects seated inside and outside a house were exposed to lowintensity $N$-wave sonic booms during a 3-week test period in June 2006. The house was instrumented to measure the booms both inside and out. F-18 aircraft were flown to achieve a variety of boom overpressures from approximately.1 to .6 psf. During four test days, seventy-seven test subjects heard the booms while seated inside and outside the house. Using the Magnitude Estimation methodology and artificial reference sounds, the subjects rated the annoyance of the booms. Since the same subjects heard similar booms both inside and outside the house, comparative ratings of indoor and outdoor annoyance were obtained. For a given metric level, indoor subjects gave higher annoyance scores than outdoor subjects. For a given boom, annoyance scores inside were on average the same as those outside. In a post-test questionnaire, the majority of subjects rated the indoor booms as more annoying than the outdoor ones. These results are discussed in this paper.

\section{Introduction}

Recent advances in aircraft design and computer simulation have stimulated interest in the possibility of supersonic flight overland. These advances are expected to enable the construction of supersonic aircraft that generate booms with shaped waveforms, rather than the traditional N-wave shape, and lower peak overpressures than are possible with current aircraft. Supersonic flight over land is at present banned by international agreement, and the question of what steps would be required to change this ruling has been raised. One step would be a greater understanding of people's response to sonic boom, which could lead to the definition of an acceptable boom level. Aircraft with shaped signatures are not currently available.

Research on the effects of sonic booms accelerated in the 1960's when the United States initiated its SuperSonic Transport program and when Great Britain and France began the development of the Concorde. This research included field surveys that investigated the response of people in the community to sonic booms heard during their normal activities.

In the field survey performed at St. Louis in 1961, the main cause of annoyance was "house shaking" (Nixon and Borsky, 1966). "For a particular sonic boom, inside exposures were lower in intensity, existed for a longer period of time, and were generally more complex in nature than the outside exposures. Subjectively, booms experienced inside were less acceptable than those experienced outside, presumably because of such factors as the longer duration, the rattling and shaking of items within the structure and the actual vibration of the structure itself."

In the extensive study performed at Oklahoma City over a 6-month period during 1964 (reported in Borsky, 1965) it was found that "[v]ibration and rattling of homes and furnishings are the most frequently reported unwanted effects of sonic booms" (Borsky, 1972). Thus it was clear the indoor environment was an important factor in determining community response to supersonic flights.

A more recent field survey conducted in two communities routinely exposed to sonic booms (Fields et $a l, 1997)$ found that the average annoyance score reported for indoor situations was higher than outdoor. 
"This difference in indoor/outdoor reactions might be expected on the basis of any of the ... major aspects of the sonic boom impact. Although it is clearest that vibration would be noticed less often outdoors, it also appears that the other aspects could also be noticed less often. Booms heard indoors may cause greater fear of danger or damage because the respondents are in a structure surrounded by things that could fall or be damaged. Booms heard indoors may be more startling because residents relax more and expect the indoor environment to generally be a more predictable noise environment or because the booms heard indoors are more likely to be associated with the possibility of danger from nearby objects." Fields reported that the leading cause of disturbance was "startle" followed by "rattles and vibration," though when each of these causes were considered separately "vibration and rattle" caused annoyance in a greater percentage of the respondents than "startle (or frighten)."

As well as these field surveys, studies of response to sonic boom have included studies performed using booms created by real flyovers under controlled conditions, including one reported by Johnson and Robinson (1967) in which they presented real sonic booms, real aircraft flyover sounds, and sounds from real explosions, together with white noise played over loudspeakers. They used the method of magnitude estimation (ME), in which the subjects compared the test sounds to a 5-second sample of white noise. "[C]onsiderations dictated the subjective test procedure, the most important being that each sound would occur once only making it impossible to introduce repeated judgements. For the same reason it was essential to obtain reliable judgements on each and every event. The method of paired comparisons [...] was impracticable and instead the method of direct magnitude estimation with prescribed modulus was adopted." They report "The listening tests were repeated outdoors and indoors, and showed that subjects were about 5 phons more severe in their judgements indoors, in conformity with previous results on conventional aircraft noise."

Kryter et al (1968), using real sonic booms and flyovers of conventional aircraft, presented pairs of sounds, boom and boom; boom and flyover; flyover and boom, to the subjects for comparative judgments. Subjects also judged the acceptability of the individual sounds on a 13 point rating scale. The results indicated that "the booms heard indoors were on the average slightly more acceptable than the same booms as heard by the subjects outdoors." As the house structure should attenuate both the noise from the aircraft flyover and the sonic boom, "it might be expected on first thought that the booms and noise would be much more acceptable indoors than outdoors. The relatively small improvement in the acceptability of the booms and aircraft noise by virtue of the listeners being indoors ... has been found to be true in previous studies of road traffic and aircraft noise... Apparently the secondary sounds or 'rattles' introduced by the nonlinear response of components of the house to the boom contribute substantially to the subjective [un]acceptability of the booms heard indoors."

Schomer et al (1997) measured reactions of test subjects located indoors and exposed to sonic booms from real aircraft, real blast sounds and a white noise. They used a Pair Comparison method in which subjects compared a white noise control sound of variable level with fixed level sonic booms and blast sounds. In this psychoacoustic methodology, a "fixed level" test sound is paired with a control sound; the pair is presented multiple times with different levels of the control sound. The subject judges which sound of the pair is more annoying. Using the responses for the different levels of the control sound, it is then possible to find a level of the control sound that is equally annoying as the test sound. Although the booms were presented as nominally "fixed level" sounds it was found that in practice their levels varied significantly. During the analysis of the data, it was found necessary to sort the boom presentations into groups based on measurements using CSEL in order to define the "fixed level" booms. The use of a specific metric may have introduced a bias into the analysis of results from this procedure. The study showed that responses to booms were similar to the responses to blast noise and CSEL calculated from outdoor sounds was a suitable metric to predict indoor response to both types of sound.

There has been a long history of studies of human response to sonic booms using simulators. Most studies have used simulations of booms as heard outdoors; however, a few have included booms that were filtered to simulate indoor conditions. 
One of the early simulator studies was performed by Pearsons and Kryter (1964) who investigated response to indoor and outdoor sonic booms. The outdoor sonic booms were simulated, but to reproduce the indoor booms the researchers used recordings of real booms recorded inside a house. They used the Method of Adjustment psychoacoustic methodology in which the subject adjusted one sound of a pair to be equally annoying as the other. The sounds included indoor and outdoor booms, aircraft flyover recordings and a $1 / 3$ octave band of noise of $6 \mathrm{sec}$ duration. For some of the booms they added a piece of plywood into the simulator, with a pane of window glass which the boom caused to rattle. For the specific boom shapes and flyover types used in their study, they found "a $2.3 \mathrm{lb} / \mathrm{ft}^{2}$ boom, measured outdoors but heard indoors, would be equivalent in acceptability to the sound heard indoors of a subsonic aircraft flyover measuring about 113 PNdB outdoors or about 98 PNdB if measured indoors." Also, for outdoor sounds, "the subjects judge a sonic boom having a peak overpressure of $2.3 \mathrm{lb} / \mathrm{ft}^{2}$ to be equivalent to the sound of a subsonic aircraft at $95.5 \mathrm{PNdB}$." They also reported "the boom with no window [rattle] was judged to be relatively much more acceptable than the boom with window [rattle] by a factor equivalent to about $13 \mathrm{~dB}$." Therefore indoor annoyance caused by a sonic boom when heard in a house with structural features that might rattle, be they windows or shelves of glassware, would be expected to be greater than that caused by the boom heard outdoors.

Leatherwood and Sullivan (1993), using the NASA Langley Sonic Boom Simulator, played simulated booms filtered to represent the transmission loss expected upon passage through the walls of a house, as well as simulated booms with outdoor waveforms. The findings indicated that loudness and annoyance were equivalent criterion measures for outdoor booms but not for indoor booms. Annoyance scores for indoor booms were significantly higher than indoor loudness scores. Thus annoyance was recommended as the criterion measure of choice for general use in assessing sonic boom subjective effects. Perceived Level was determined to be an effective estimator of annoyance for both indoor and outdoor booms. The indoor booms used in this study had no rattle or vibration components.

Pearsons et al (1993, unpublished) positioned subjects inside and outside a house structure and exposed them to simulated sonic booms and recorded transportation sounds. Indoor and outdoor testing was conducted simultaneously with groups of subjects randomly assigned to one or the other location. Subjects were required to rate the sounds they heard on an absolute judgment scale with five categories labeled "Not at all annoying", "Slightly annoying", "Moderately annoying", "Very annoying" and "Extremely annoying." In some cases dishes were positioned inside the house in order to create rattles. Rattle was audible during boom presentations, but no quantitative analysis was reported. No statistically reliable main effect was found for rattle. The annoyance ratings given by indoor subjects to booms of a given ASEL as measured indoors were found to be greater than ratings given by outdoor subjects to booms of the same ASEL values as measured outdoors. To produce ratings between "slightly" and "moderately annoying," sounds heard (and measured) outdoors were found to have ASEL levels about 13 $\mathrm{dB}$ greater than sounds heard (and measured) indoors. This difference increased with increasing level.

Fidell et al (2002), using a low-frequency test facility, played simulated indoor booms, noise bursts and a recorded aircraft flyover to subjects who rated their annoyance. In some cases, recorded rattle was added to the simulated booms in "at such a low level that it did not meaningfully affect their A- or Cweighted SEL values." Judgments were found to depend on the type of sound in a way that was not accounted for by ASEL. A statistically significant effect of rattle was found, with rattle adding an effective $5 \mathrm{~dB}$ to the annoyance caused by the boom.

The influence of rattle was included in a laboratory study by Cawthorn et al (1978) in which they played recorded aircraft flyover sounds to subjects in a simulated living room setting. Independentlycontrolled rattle sounds were added but "the presence of rattle did not, in any practical sense, affect the subjective response to aircraft noise." Their rattle levels were too low to affect the A-weighted level of the aircraft noise.

Schomer and Neathammer (1987) investigated the influence of rattle on response to helicopter flyover 
noise. They report "With no vibrations or rattles, the helicopter is equal to or less annoying than the control [sound] for the same A-weighted SEL. However, when a little vibration or rattling is present the helicopter SEL offset is on the order of $12 \mathrm{~dB}$; when a lot of vibration is present the offset exceeds 20 dB." The "vibration and rattle" present in the test sounds was divided into "none", "a little" and "a lot," based on the "researchers' subjective evaluation of the vibration and rattles present."

In a study of blast noise, Schomer and Averbuch (1989) reported an effect of rattle that produced a change in subjective response equivalent to a change in ASEL of $13 \mathrm{~dB}$ for low blast levels and $6 \mathrm{~dB}$ for high blast levels. The addition of the rattle caused a change in measured ASEL of only about 1 decibel.

Based on field surveys (Borsky (1965), Nixon and Borsky (1966), Fields et al (1997)) it is clear that indoor phenomena (fear of damage, vibration/shaking and rattle) are important contributors to residents' annoyance to sonic boom exposure. Controlled experiments (Johnson and Robinson (1967), Kryter et al (1968)) in which test subjects evaluated sonic booms in both indoor and outdoor listening conditions indicate that the difference between indoor and outdoor annoyance is not what would be expected from the fact that indoor sound levels are substantially lower than outdoor levels. These results indicate that test subjects do not simply evaluate the sonic boom that they hear; other factors such as the indoor phenomena mentioned above, other acoustical factors and perhaps expectations of indoor quiet may be relevant.

Other experiments in which the sound of rattling objects was intentionally introduced into the test environment provide inconsistent conclusions; the "penalty" due to rattle has been variously reported to range from 0dB (Pearsons et al (1993), Cawthorn et al (1978)) to $5 \mathrm{~dB}$ (Fidell et al (2002)) and as high as 13-20 dB (Schomer and Neathammer (1987), Pearsons and Kryter (1964), Schomer and Averbuch (1989)).

The present study is focused on the investigation of indoor and outdoor annoyance to low amplitude sonic booms. The range of amplitudes encompasses those that might be achievable with a new class of supersonic vehicles. Particular objectives include an assessment of the relative importance of indoor and outdoor listening conditions and the examination of noise metrics' ability to predict annoyance in both environments. Rattle was present in the indoor sounds, but was not controlled in this test.

\section{Symbols and Abbreviations}

$\begin{array}{ll}\mathrm{dB} & \text { decibels re } 0.00002 \mathrm{~Pa} \\ \text { ASEL } & \text { A-weighted sound exposure level, } \mathrm{dB} \\ \mathrm{CSEL} & \text { C-weighted sound exposure level, } \mathrm{dB} \\ \text { ZSEL } & \text { unweighted sound exposure level, dB } \\ \text { LLZd } & \text { Calculated Loudness Level (Zwicker's method, diffuse incidence), phons } \\ \text { LLZf } & \text { Calculated Loudness Level (Zwicker's method, frontal incidence), phons } \\ \text { Mgstat } & \text { Moore and Glasburg stationary loudness, phons } \\ \text { MGTS } & \text { maximum Glasburg and Moore short-term time-varying loudness level, phons } \\ \text { MGTL } & \text { maximum Glasburg and Moore long-term time-varying loudness level, phons } \\ \text { Pa } & \text { Pascals } \\ \text { PL } & \text { Perceived Level (Stevens' Mark VII), dB or phons } \\ \text { Pmax } & \text { Maximum overpressure } \\ \text { PNL } & \text { Perceived Noise Level, dB } \\ \text { psf } & \text { pounds force per square foot }\left(\mathrm{lb}_{\mathrm{f}} / \mathrm{ft}^{2}\right)\end{array}$

\section{Objectives of Study}

A flight maneuver has been developed that enables a low-intensity $\mathrm{N}$-wave to be received at the ground (Haering, 2006) (see figure 1). The intensity and location of the boom at the ground are 


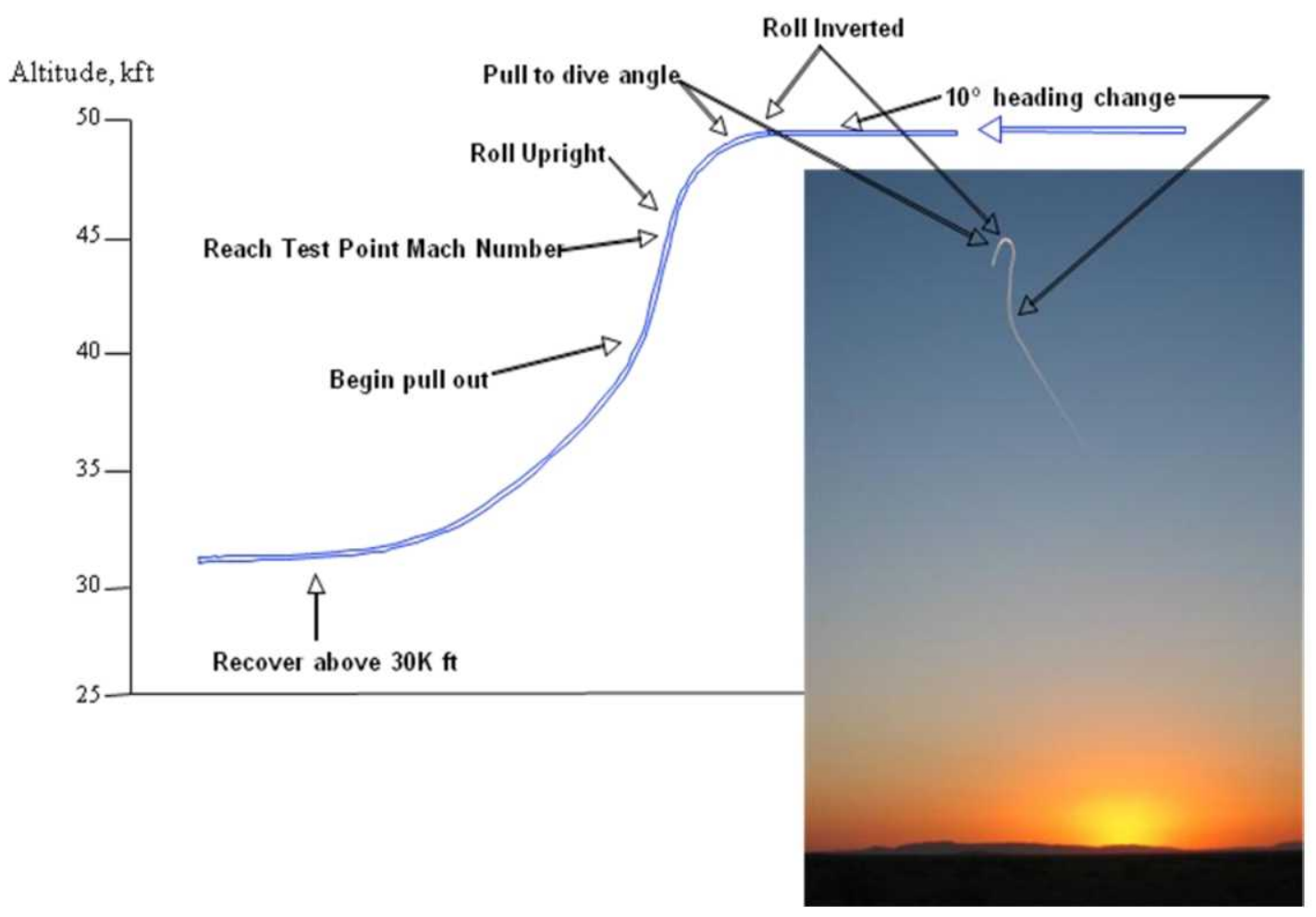

Figure 1 - NASA Dryden "low boom" flight maneuver.

controllable, given knowledge of the atmospheric conditions. By varying the trajectory of the aircraft, different intensities of boom can be positioned at a given point on the ground. These boom intensity levels are much lower than those from the same aircraft in level flight.

An experiment was designed to use low-amplitude $\mathrm{N}$-waves to investigate three issues:

- Investigate effects of atmospheric turbulence on boom propagation

- Record building vibration and acoustic responses for use in structural model development and validation

- Investigate subjective response to booms heard inside and outside a structure, including effects of rattle and vibration.

The first two items are documented elsewhere (Locey and Sparrow, 2007; Klos and Buehrle, 2007). The third purpose of the flight test is reported here. A psychoacoustic study was conducted with the objective of comparing human response to low-intensity booms when heard outside and inside a house of standard construction.

\section{Test Location}

An unoccupied house on Edwards AFB was selected for the test (see figure 2). The house was empty and due to be demolished soon after the conclusion of the study. It was built in approximately 1960s, and was in poor repair. The windows were very loose, causing remarkably strong rattle sounds inside the house when impacted by a sonic boom. This was important because of the indications that rattle and vibration are significant contributors to annoyance from booms and other impulsive sounds heard indoors, as reported in the introduction above. One group of test subjects was located in the living area which was carpeted to reduce reverberation. Another group was located in the back yard of the house. 


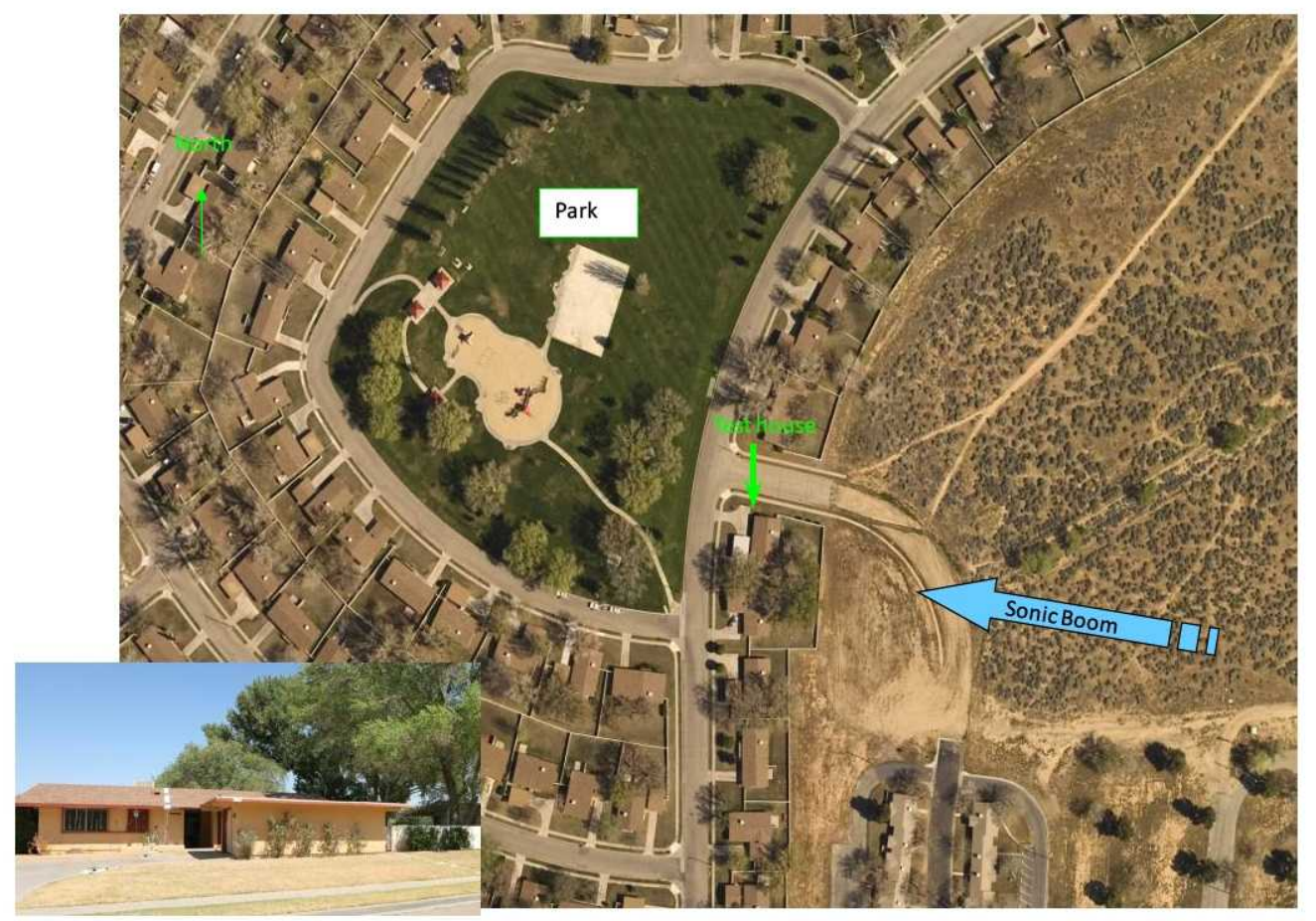

Figure 2 - Test residence at Edwards Air Force Base.

\section{Test Design}

Two F-18 aircraft flew the flight maneuver during the experiment. In order to produce varying boom intensities at the test house, a series of locations for the dive maneuver was defined based on distance and measured atmospheric conditions. During the test, the test house received a boom every three minutes, with a total of 12 booms per test session. After the first session of the day, the two aircraft were refueled and the procedure was repeated for 12 more booms. Thus one "test day" consisted of two sessions with 24 booms.

The test design required test subjects to rate 24 low-intensity sonic booms, 12 heard while indoors and 12 while outdoors. The booms were presented at four nominal overpressure levels $(0.11,0.19,0.33$ and $0.56 \mathrm{psf})$. These levels were selected to be within the range of interest and to be separated by equal intervals on a logarithmic scale $(6 \mathrm{~dB})$. The subjects heard three presentations of each level at each listening location. They also rated two synthesized sounds: a simulated boom and a band of noise. At each listening location, the subjects heard the simulated boom played once at each of four levels, and the band of noise played twice at each of four levels. Thus at each location, there was a total of 24 presentations of test stimuli, 12 real booms and 12 synthesized sounds.

There were four test days, with 20 test subjects planned for each day, for a total of 80 people. Each group of 20 subjects was divided into two groups of 10 . One group sat inside the house and the other outside for the first test session. At the conclusion of that session, the two groups exchanged places. The boom levels were nominally the same for the two sessions, indoors and out, though the presentation order was varied. At the end of the test day, the subjects were asked to complete a questionnaire to elicit their overall impression of the sounds they had heard. The questionnaire is presented in Appendix A.

\section{Test Stimuli}

The booms created by the dive maneuver are $\mathrm{N}$-waves that travel large distances before reaching the 

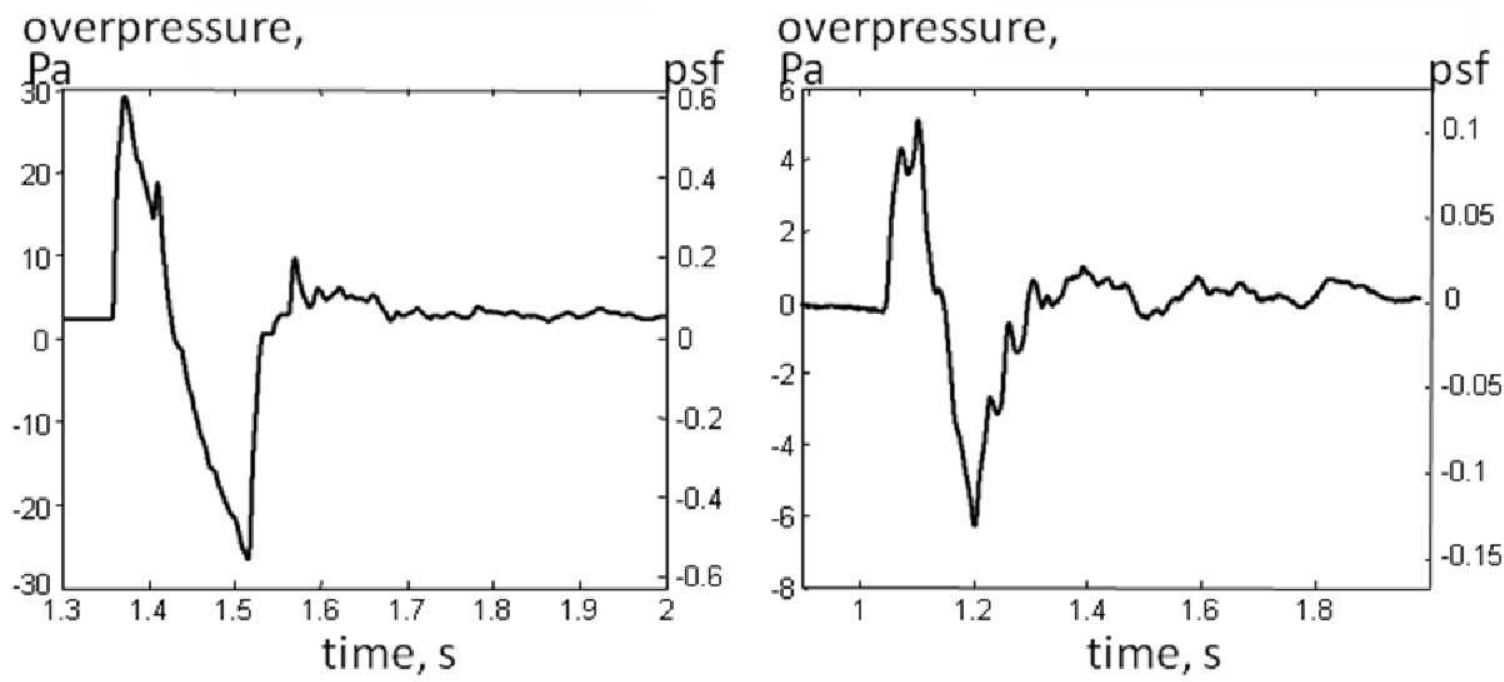

Figure 3 - Example low-intensity N-wave waveforms.

ground, and thus are very rounded with long rise times and low amplitudes (see figure 3). They are unlike the waveforms predicted to be produced by low boom aircraft designs, which are generally shaped booms (see figure 4). (A description of sonic boom waveforms is given in Maglieri and Plotkin, 1991.) However, they are the only low-amplitude booms available from present-day aircraft, and as such were the only test stimuli available for this study. Low-intensity booms ranging from 0.1 to 0.6 psf peak overpressure on the ground were selected for presentation to subjects. Outdoor ASEL values for these booms were predicted to range from about 45 to $65 \mathrm{~dB}$.

The reference stimulus chosen was based on a comparison sound used by Schomer et al $(1994,1997)$. A band of white noise, band-pass filtered from $200 \mathrm{~Hz}$ to $1500 \mathrm{~Hz}$, was faded up in intensity for $150 \mathrm{~ms}$, held steady for $150 \mathrm{~ms}$, and faded down for $150 \mathrm{~ms}$.

The synthesized test stimuli were a band of white noise, filtered from $400 \mathrm{~Hz}$ to $2000 \mathrm{~Hz}$, of the same temporal shape as the reference stimulus, and a simulated boom. The simulated boom was an N-wave of $150 \mathrm{~ms}$ duration with a rise time approximately $3 \mathrm{~ms}$, high pass filtered at $50 \mathrm{~Hz}$ for presentation over conventional loudspeakers.

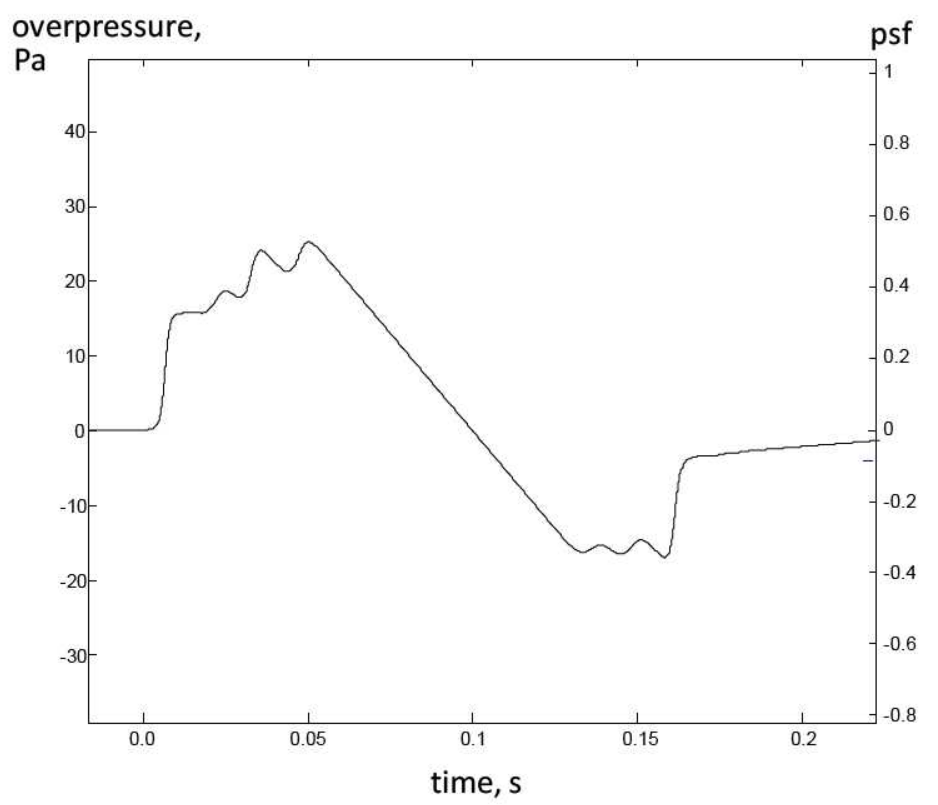

Figure 4 - Example predicted shaped boom waveform. 


\section{Response Methodology}

As the objective of this study was to compare indoor and outdoor annoyance to sonic booms, a test method had to be designed that would enable results for the indoor ratings to be directly compared with the outdoor ratings. The psychometric methods of Paired Comparison and Constant Stimulus Difference (Guilford, 1954), in which sounds are judged in pairs, require multiple presentations of exactly the same stimulus. However, sonic booms vary in an uncontrolled manner due to atmospheric conditions. If a very large number of booms could be presented, then many repetitions might produce a sufficient number of similar booms to enable analysis of results from paired methodologies to be possible. For this test, only limited numbers of booms were available. In the method of Category Scaling (Guilford, 1954) sounds are judged along a scale of some description, for example from "not at all annoying" to "extremely annoying." This method has the problem that it was not known if subjects would use the scale in the same way indoors and outdoors. For example, subjects might arrange the sounds along the entire scale in each listening location, without consistent use of the scale words.

In the method of Magnitude Estimation (Stevens, 1956), subjects compare a "test" sound with a "reference" sound, and give the test sound a ratio rating. For example, the reference sound could be assigned a value of 10 on a scale of, for instance, loudness. Then if the subject assesses the test sound as being twice as loud, he or she would rate it as 20 . If it was considered half as loud, the test sound would be rated at 5 . One advantage of this method is that each presentation of a test sound is considered by the subject separately from all other test sound presentations, so the inability for a boom to be repeated exactly would not be a problem. Also, if the reference sound is the same inside and outside, the ratings of booms heard inside and outside should be directly comparable. A band of noise was selected for the reference rather than an impulsive stimulus like a synthesized boom because of the difficulty of making an impulsive stimulus sound the same indoors and outdoors due to room reverberation effects. The comparison of simulated sonic booms to a band of noise was found to present no problems to subjects during a pilot study conducted at NASA Langley Research Center (see Appendix B).

The Magnitude Estimation (ME) technique has been used at NASA Langley Research Center when measuring the responses of people to simulated sonic booms heard in the Sonic Boom Simulator (see for example Leatherwood et al, 2002). The technique has been found to be very effective, once the subject has been instructed in the method. It has been found (McDaniel et al, 1992) that subjects prefer the reference stimulus to be repeated sufficiently often that they feel no fear of forgetting it. Due to the long interval between booms in this test, the reference stimulus was presented before every boom. The reference stimulus was always presented at the same level.

The subjects were asked to compare the sounds they heard using the criterion "annoyance." Test instructions and a sample response sheet are given in appendixes C and D. In summary, the test instructions were: "Your task will be to tell us just how annoying each of the other sounds is as compared to the reference sound." The reference sound was given a value of 100 . If the subject did not hear the test stimulus, they were instructed to write a rating of zero.

In order that the reference stimulus would be as similar as possible in the two listening locations, indoors and out, it was presented over a loudspeaker close to and behind the subject's head. Thus the subject was within the near field of the speaker and the sound heard indoors would be minimally affected by the room acoustics, and would be very similar to the outdoor sound. A row of chairs for the subjects was set up and a row of loudspeakers on tripods was positioned behind them, at approximately head height and 20 inches behind the head position (see figure 5). The same speakers were used for the presentation of the synthesized test stimuli. 


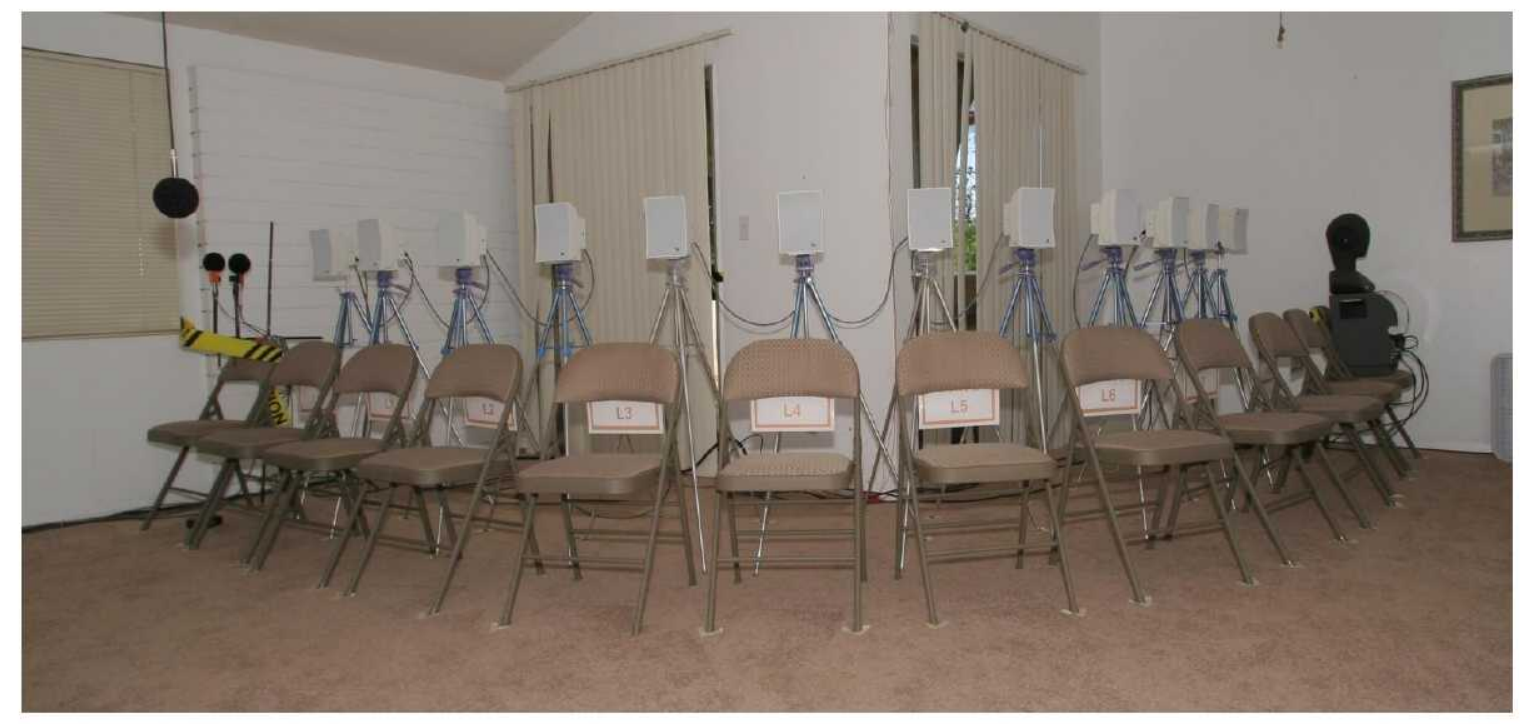

Figure 5. - Indoor listening location showing the row of 12 chairs with a loudspeaker positioned behind each chair.

\section{Test Stimuli Levels}

Four nominal boom amplitudes were selected for presentation during the test, which were considered to cover an expected range of responses from probably unacceptable to possibly acceptable. The selected amplitudes were $0.11,0.19,0.33$ and 0.56 psf. Based on previous recordings of low-intensity $\mathrm{N}$-waves, these values were expected to give outdoor ASEL values of 47, 53, 59 and $65 \mathrm{~dB}$. During an initial survey of the test house, the insertion loss in the house was calculated to be $10 \mathrm{~dB}$ ASEL, which would result in indoor ASEL values of 37, 43, 49 and $55 \mathrm{~dB}$. Because each sonic boom is affected differently by passage through the atmosphere, the precise exposure varied from the nominal values.

An ASEL value of $57 \mathrm{~dB}$ was chosen for the reference stimulus based on the expected range of boom levels and the background noise levels at the site. ASEL was used to define the reference level, because it is easy to measure and is a reasonable estimate of loudness. The literature indicates that rattle and vibration are important factors, so it was expected that indoor booms would produce more annoyance than their A-weighted level would predict. Thus the level chosen for the reference sound was relatively high compared to the expected indoor boom levels.

As reported earlier, in order to keep the subjects responding in the same manner indoors and outdoors, the reference level was designed to be the same indoors and out. However, due to a misalignment of the amplifier gain controls, the presentation levels used for the reference sound and the synthesized sounds during the test were found to differ by about $2 \mathrm{~dB}$ between inside and outside. The measured presentation ASEL values for the reference sound, averaged across the seats, were $59.1 \mathrm{~dB}$ outside and $56.9 \mathrm{~dB}$ inside.

The synthesized test sounds were nominally played at 45, 50, 55 and $60 \mathrm{~dB}$ ASEL. These levels were planned to be the same in both listening locations, inside and out; however, the $2 \mathrm{~dB}$ gain misalignment affected these as well. The predicted range of all indoor test stimuli was 35 to $60 \mathrm{~dB}$ ASEL, and the range of outdoor test stimuli was 45 to $65 \mathrm{~dB}$.

\section{Test Stimuli Timing}

The reference stimulus was presented approximately 20-30 s before the expected time of arrival of 
(a)

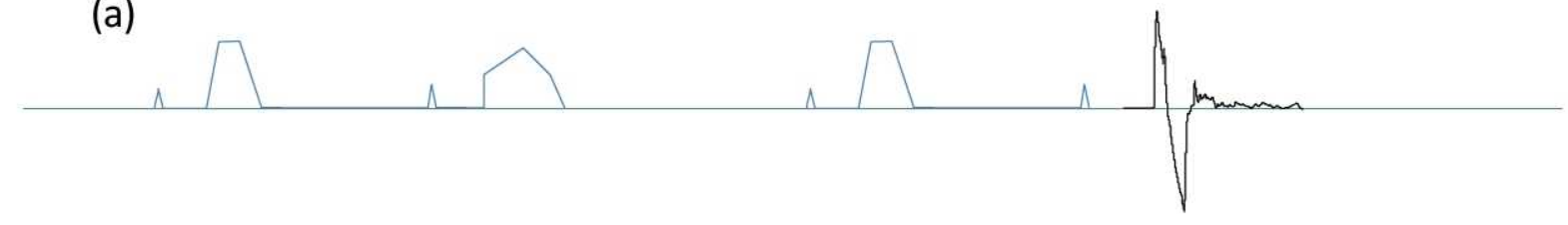

(b)

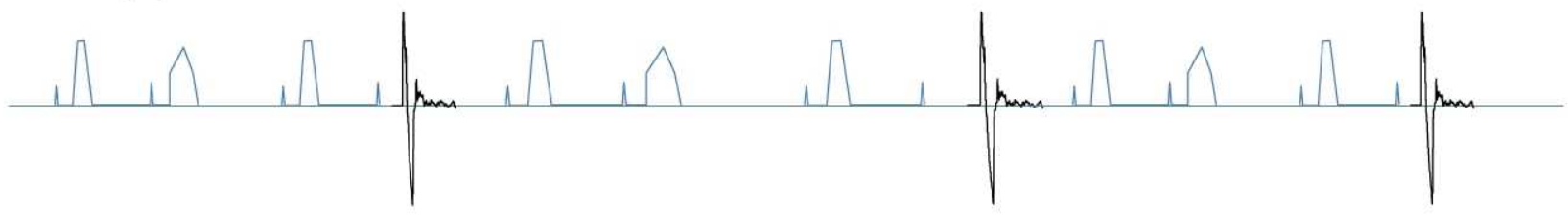

Figure 6 - (a) Sketch of sequence of voice cue, reference sound, voice cue, synthesized test sound, voice cue, reference sound, voice cue, real boom; (b) sequence repeated three times.

each boom. Each presentation of the reference stimulus was preceded by a voice cue saying "Reference." The expected interval between booms was about 3 minutes. Approximately 1.5 minutes before each real boom sound, one of the synthesized sounds was presented, preceded by the reference stimulus. As there were inevitably other sounds audible in the subjects' vicinity, especially for those sitting outdoors, a voice cue ("judge now") was added after each test stimulus, including the real booms, telling the subjects when to write down their ratings. The computer-controlled playback system played the "reference" cue, the reference stimulus, and the "judge now" cue to both indoor and outdoor groups of subjects simultaneously. The sequence of events is illustrated in figure 6.

The precise time of arrival of each boom could not be predicted and therefore the time interval between the presentation of each reference stimulus and its succeeding boom was varied. The interval was designed to be between 20 to $40 \mathrm{~s}$, but in practice the variation was somewhat larger. Additionally the time between booms was not constant. In a similar manner, the presentation times of the synthesized test stimuli were varied randomly, as was the time of the preceding reference stimulus and the following "judge now" voice cue, so that no timing pattern would be discernible to the subjects.
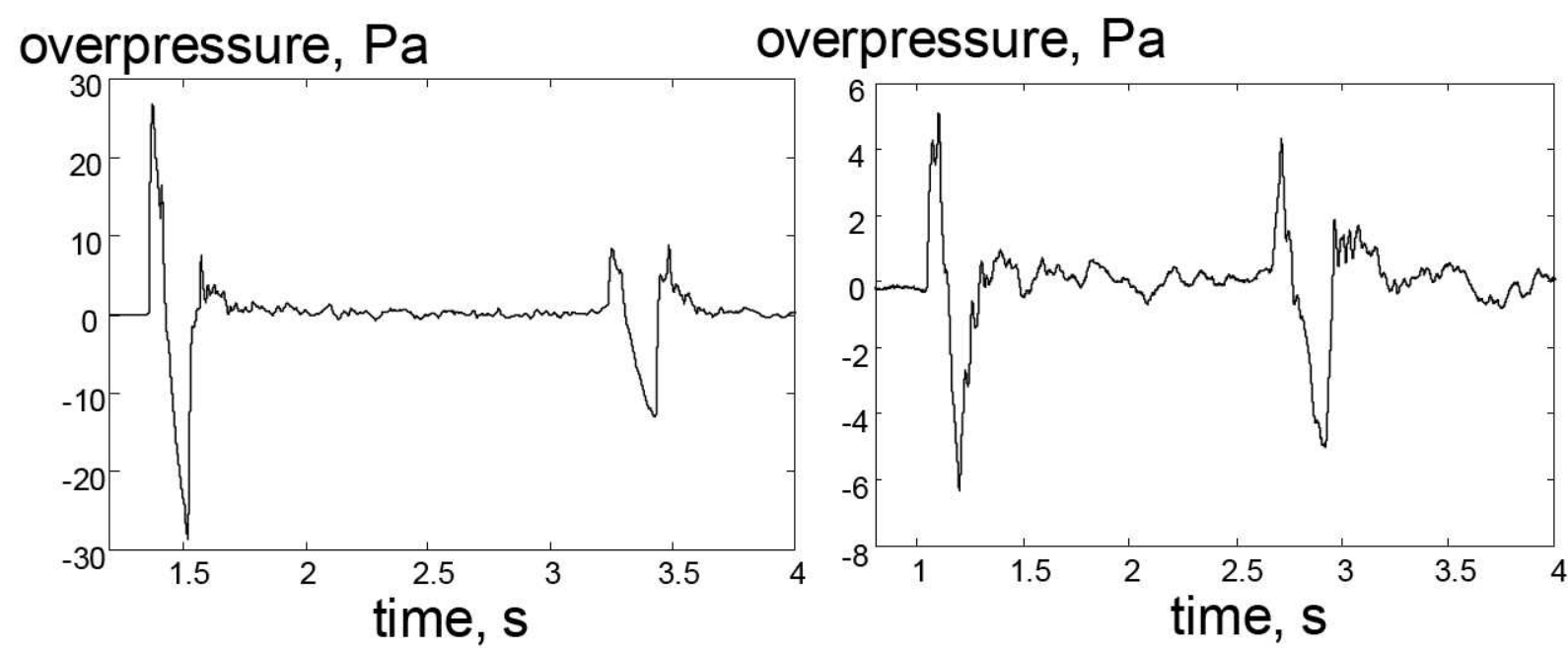

Figure 7 - Example waveforms showing low-intensity N-wave followed by secondary boom. 
The maneuver used to generate the low-intensity booms included an acceleration and dive, which resulted in the test house being impacted by the planned primary boom and also by a secondary boom that was generated at another point along the flight path. In general, these secondary booms were U-wave shapes that followed the primary boom by a few seconds (see figure 7). The U-waves booms were of lower intensity and longer rise time, and thus lower loudness level, than the primary $\mathrm{N}$-waves. There was insufficient time between the primary and secondary booms for the "judge now" voice cue to be played, and for the subjects to make a judgment and write it down. Therefore the voice cue was played after the secondary boom. During the instruction period, the subjects were informed they might hear double sounds and that they were to judge the entire event (described as "boom-boom boom-boom"). Inside the house the secondary boom was less obvious because of the continuing rattle sounds caused by the primary boom.

\section{Experimental Layout}

A line of 12 seats was placed in an arc in the indoor listening area (see figure 8), and a loudspeaker was positioned behind each seat. All 12 loudspeakers were supplied with the same signal. Preliminary testing showed that the sound from adjacent speakers interacted with the sound from the speaker directly behind a seat. Therefore to ensure similar sounds at all subject positions, the seats at the two ends of the arc were not used, as these seats did not have adjacent speakers on both sides. This resulted in seating for ten subjects.

To make the indoor and outdoor listening conditions as similar as possible, the same arc was replicated outdoors, in the back yard of the house in the shade of a tree (see figure 9). Subjects spent part of the test day inside and part outside. In order to keep their exposure conditions the same, each subject was seated in the same position in the row of seats inside as $\mathrm{s} / \mathrm{he}$ was outside. The outdoor speakers and chairs were set up daily.

\section{Test Procedure}

Subjects were recruited by placing advertisements in local communities near Edwards Air Force Base. All volunteers were screened for hearing within $40 \mathrm{~dB}$ of normal over the frequency range of $500 \mathrm{~Hz}$ to $6,000 \mathrm{~Hz}$, and were given a short training session to enable them to become familiar with the magnitude estimation rating technique. This occurred a few days before the test began. The sounds used in the training session included synthesized booms and noise bursts, similar to those used in the test.

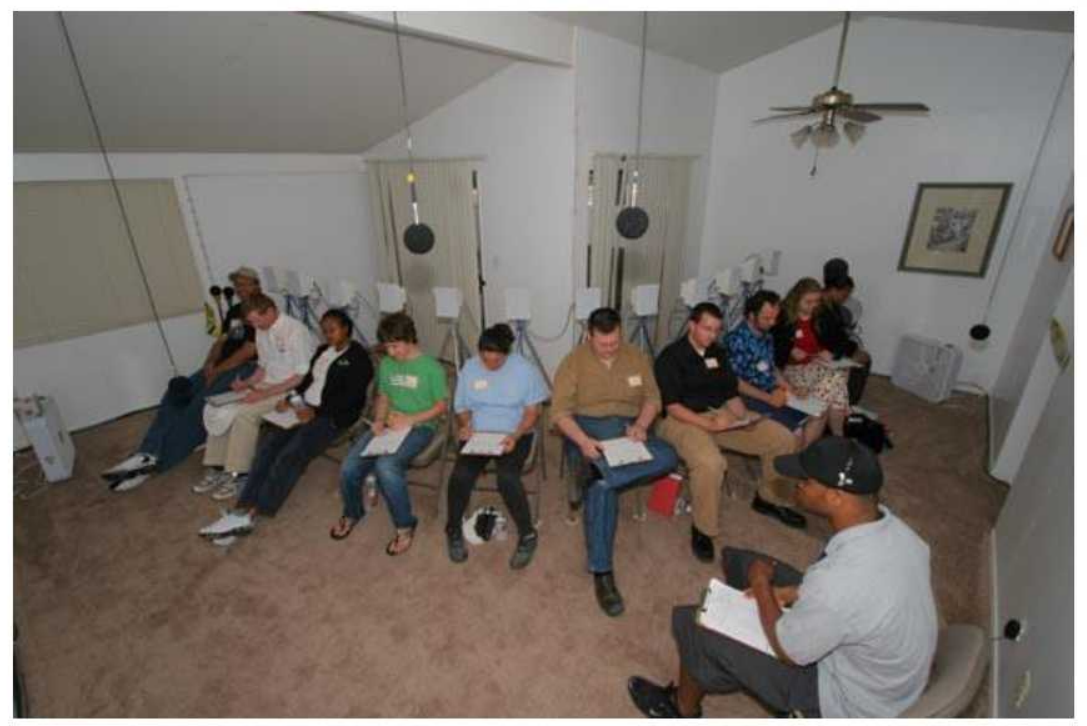

Figure 8 - Indoor listening location with subjects. 


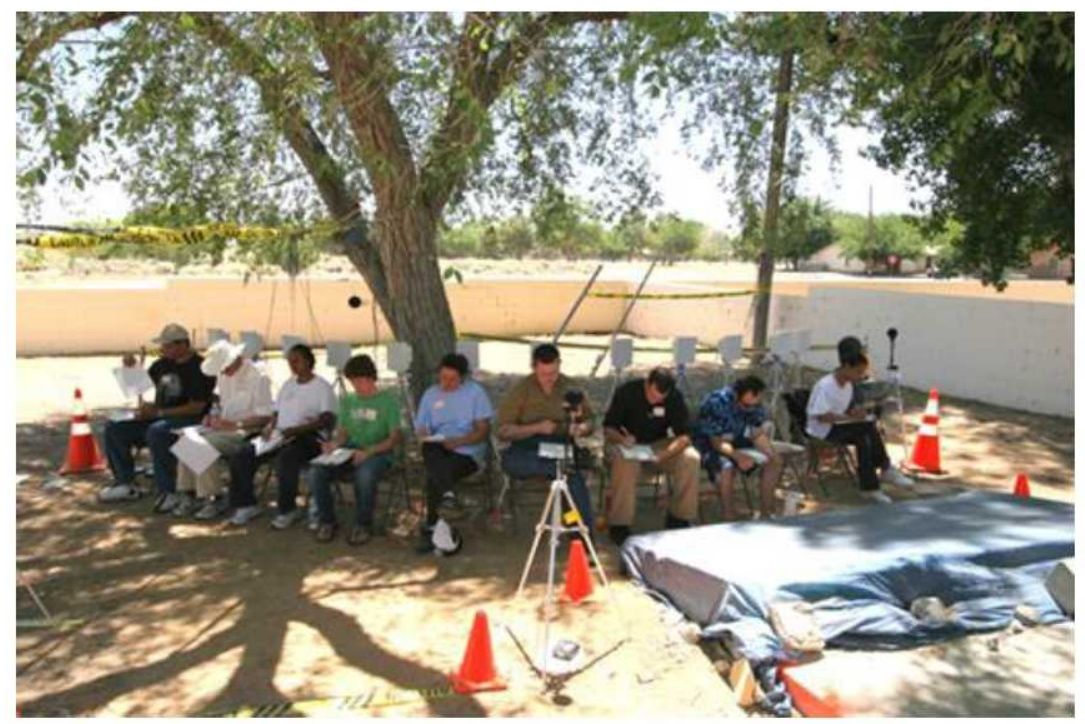

Figure 9 - Outdoor listening location with subjects.

On each test day, before the arrival of the subjects, measurements of selected synthesized sounds were made in each of the subject seats to ensure speaker reproduction was consistent. On each day of the test, subjects were brought to the test house, and given their instructions. After signing an informed consent form, they were given another training session, to remind them of the rating technique. They were then divided into two groups and seated in the test locations, one group indoors and one outdoors. They were then given a practice session, so that they could hear the reference sound in situ and get used to comparing other sounds to that particular sound. The test stimuli used in the practice session consisted of some of the synthesized sounds.

There was then a pause until the test director was informed that the aircraft were about to take off. Before the first boom was heard, the reference stimulus was played twice more, the first synthesized stimulus was played and rated by the subjects, and the reference stimulus was repeated. The pattern of reference - synthesized stimulus - reference - boom continued to the end of the session. During the aircraft refueling period, snacks and drinks were available for the subjects, who were discouraged from discussing the test with each other. The two groups of subjects then exchanged listening locations.

The second test session used the same procedure as the first test session. Each group of subjects was monitored throughout the test. When the second test session was completed, the subjects were asked to fill out a questionnaire, and were then taken to a location were post-test audiograms were completed, as required by safety procedures, to ensure no temporary hearing loss had been sustained during the experiment.

\section{Safety Measures}

In accordance with approved psychoacoustical protocols at NASA Langley Research Center, the sounds heard by the subjects were monitored by microphones positioned near the listening positions. These microphones were connected to a limiting system, consisting of sound level meters and a relay. If levels exceeded $95 \mathrm{~dB}$ (measured using A-weighting and slow response) or $140 \mathrm{~dB}$ (instantaneous unweighted peak), it would transmit a signal that was used to trigger the relay, causing the computer program that was playing back the reference sound, synthesized test stimuli and voice cues to halt. There were no such incidents during the course of the test. The levels of all the sounds heard by the subjects, booms, synthesized sounds, and any other noises were recorded using the sound level meters as an archival record of the subjects' sound exposure. 


\section{Acoustical Measurements}

The house was instrumented inside with accelerometers and microphones; additionally, outside microphones were placed near the house, on its walls and roof, and in the subjects' area, as well as in the far field, to obtain boom signatures unaffected by near-by buildings.

Recordings were made of the real booms by many microphones for the structural response study as well as the human response test. Data presented in this report are from a microphone suspended in the indoor listening area and a microphone at ground level in the back yard. A ground-level microphone was used to measure outdoor data rather than a microphone at ear height, because the use of a ground-level microphone is standard practice in the measurement of sonic booms. Comparisons between the groundlevel microphone and a nearby microphone located $1.2 \mathrm{~m}(4 \mathrm{ft})$ above the ground showed that calculated metric levels are highly correlated (see Appendix E). Recordings of the primary and secondary booms were analyzed to calculate metric levels.

During the equipment set-up phase of the study, the reference sound was measured at each subject position, in the absence of subjects. The range of ASEL levels of the reference sound at the 10 subject locations was found to be $1.1 \mathrm{~dB}$ indoors and $0.8 \mathrm{~dB}$ outdoors, with a difference in the average level of $0.2 \mathrm{~dB}$. On each of the four test days, before the arrival of the subjects, the level of the reference sound was measured at each of the subject seats. At the end of the first test day, analysis showed that the ASEL levels of the reference sound measured outdoors were consistently higher than the indoor levels. This discrepancy was maintained for all the test days. The measured range across seats and days was $2.6 \mathrm{~dB}$ outdoors and $2.0 \mathrm{~dB}$ indoors, with a difference between the average indoor and outdoor levels of the reference stimulus of $2.2 \mathrm{~dB}$. This discrepancy is presumed to be due to a misalignment of the volume controls which was preserved throughout the test. For metric calculation, the synthesized sounds were recorded at each subject position, in the absence of subjects, at the levels used during the test.

\section{Results}

\section{Sonic Boom Levels}

On two of the four days, fewer than the scheduled numbers of 24 booms were received because of aircraft or communications problems. In all, 91 booms were rated by the subjects during the test. The initial test day was affected by the weather: relatively strong winds caused significant background noise in the back yard, due to the rustling of leaves in the shade tree over the subject location. During the second test day, some leaf noise was also present. Measured booms levels differed from nominal values, mainly due to variability in atmospheric conditions that occurred over the long propagation distances. The atmospheric effects were particularly noticeable on the first test day. Some level variation was expected; the chosen psychoacoustic method (magnitude estimation) is relatively robust to such variability. Level data for each of the four test days as measured at a microphone situated in the back yard of the house are summarized in Table 1 and Table 2; each table entry represents the average and range of up to 6 booms. Table 3 presents the same data for ASEL from data measured by the microphone in the indoor listening area.

Table 1 - Sonic Boom Maximum Overpressure, psf, for outdoor booms

\begin{tabular}{|l|l|l|l|l|l|l|l|l|}
\hline \multirow{2}{*}{$\begin{array}{l}\text { Nominal } \\
\text { level }\end{array}$} & \multicolumn{2}{|l|}{ Day 1 } & \multicolumn{2}{l|}{ Day 2 } & \multicolumn{2}{l|}{ Day 3 } & \multicolumn{2}{l|}{ Day 4 } \\
\cline { 2 - 9 } & Ave & Range & Ave & Range & Ave & Range & Ave & Range \\
\hline 0.11 & 0.11 & $0.04-0.19$ & 0.30 & $0.17-0.54$ & 0.21 & $0.11-0.34$ & 0.27 & $0.19-0.40$ \\
\hline 0.19 & 0.07 & $0.04-0.10$ & 0.28 & $0.19-0.38$ & 0.31 & $0.20-0.46$ & 0.29 & $0.21-0.39$ \\
\hline 0.33 & 0.16 & $0.09-0.20$ & 0.46 & $0.25-0.59$ & 0.27 & $0.21-0.33$ & 0.40 & $0.24-0.70$ \\
\hline 0.56 & 0.44 & $0.33-0.62$ & 0.54 & $0.34-0.73$ & 0.58 & $0.40-0.80$ & 0.51 & $0.48-0.56$ \\
\hline
\end{tabular}


Table 2 - Sonic Boom A-weighted SEL, dB, for outdoor booms

\begin{tabular}{|l|l|l|l|l|l|l|l|l|}
\hline \multirow{2}{*}{$\begin{array}{l}\text { Nominal } \\
\text { level }\end{array}$} & \multicolumn{3}{|l|}{ Day 1 } & Day 2 & \multicolumn{2}{l|}{ Day 3 } & Day 4 \\
\cline { 2 - 9 } & Ave & Range & Ave & Range & Ave & Range & Ave & Range \\
\hline 47 & 55.3 & $50.4-60.2$ & 60.5 & $55.9-75.2$ & 52.3 & $47.9-60.1$ & 51.8 & $48.7-58.2$ \\
\hline 53 & 53.8 & $52.5-55.8$ & 62.0 & $59.8-65.5$ & 54.4 & $49.0-61.1$ & 56.5 & $48.0-62.9$ \\
\hline 59 & 58.0 & $55.2-60.4$ & 66.6 & $60.2-71.5$ & 55.4 & $52.6-57.5$ & 61.1 & $54.2-68.3$ \\
\hline 65 & 67.9 & $60.2-76.6$ & 74.1 & $70.5-77.4$ & 69.0 & $61.9-77.3$ & 65.6 & $64.5-66.5$ \\
\hline
\end{tabular}

Table 3 - Sonic Boom A-weighted SEL, dB, for indoor booms

\begin{tabular}{|l|l|l|l|l|l|l|l|l|}
\hline \multirow{2}{*}{$\begin{array}{l}\text { Nominal } \\
\text { level }\end{array}$} & \multicolumn{3}{|l|}{ Day 1 } & Day 2 & Day 3 & \multicolumn{2}{l|}{ Day 4 } \\
\cline { 2 - 9 } & Ave & Range & Ave & Range & Ave & Range & Ave & Range \\
\hline 37 & 42.3 & $40.9-45.5$ & 52.1 & $48.9-57.7$ & 44.0 & $39.3-50.3$ & 47.7 & $44.2-54.0$ \\
\hline 43 & 42.6 & $40.9-44.5$ & 51.6 & $50.4-52.6$ & 49.8 & $43.8-54.8$ & 49.8 & $45.7-54.0$ \\
\hline 49 & 46.4 & $43.3-49.1$ & 55.0 & $50.8-57.2$ & 48.9 & $46.1-50.6$ & 53.2 & $46.7-59.0$ \\
\hline 55 & 54.3 & $50.5-59.5$ & 57.8 & $53.2-60.2$ & 57.6 & $52.7-61.4$ & 56.4 & $55.9-57.4$ \\
\hline
\end{tabular}

\section{Acoustical Analyses}

Metrics calculated included: maximum overpressure, sound exposure level (SEL) (ANSI, 2005) with different weightings (A, C and unweighted), calculated metrics based on 1/3 octave band analyses: calculated loudness level using Zwicker's method (LLZ) (Zwicker et al, 1991), calculated Perceived Level using Steven's Mk VII method (PL, Stevens, 1972), Perceived Noise Level (PNL, Pearsons and Bennett, 1974), and stationary and time-varying loudness levels using algorithms developed by Glasburg and Moore (Glasburg and Moore, 2002, 2006).

SEL measures were calculated using the standard 1-s normalization time. PL was calculated based on the procedure defined by Johnson and Robinson (1969) which uses a 70-ms normalization time. LLZ and PNL were calculated using the same 70-ms normalization time.

In some instances the background noise affected the metric values calculated for the sonic booms. An estimate of the background noise level was made by analyzing a segment of the signal that immediately preceded each boom. It was decided to reject metric data in further analyses if the background noise was within $5 \mathrm{~dB}$ (ASEL) of the boom. Of the 91 booms used in the test, 20 were rejected, leaving 71 booms with acceptable signal-to-noise ratio.

Metrics used in the analyses presented here were calculated for two microphone locations. One microphone was situated on a ground board in the back yard of the house near to the outdoor subjects' locations. The other microphone was suspended in the room with the test subjects. Table 4 shows the mean, maximum and minimum differences between the outdoor and indoor levels for 11 metrics for the 71 booms with acceptable signal-to-noise ratio.

All metrics for both locations were found to be highly correlated, which is expected for N-wave sonic booms, because of the interdependence of level and rise-time, and hence spectrum. Details of the correlations are shown in Appendix E. Correlations are significant at the $p<0.0001$ level for all metric comparisons, including those between indoor and outdoor measurements, and between metrics calculated for the primary $\mathrm{N}$-wave alone and for the primary and secondary booms combined. 
Table 4 - Mean, maximum and minimum differences between the outdoor and indoor levels

\begin{tabular}{|l|l|l|l|}
\hline & Mean & Maximum & Minimum \\
\hline Pmax & 0.2385 & 0.51 & 0.09 \\
\hline ASEL & 9.1324 & 17.93 & 0.83 \\
\hline CSEL & 8.2975 & 11.24 & 6.01 \\
\hline ZSEL & 7.6837 & 9.40 & 3.94 \\
\hline LLZd & 5.4768 & 9.88 & 2.32 \\
\hline LLZf & 5.6062 & 9.63 & 2.58 \\
\hline PL & 7.7477 & 15.04 & 0.04 \\
\hline PNL & 9.0669 & 16.67 & 1.07 \\
\hline Mgstat & 0.8141 & 8.10 & -7.20 \\
\hline MGTS & -0.8990 & 9.55 & -11.58 \\
\hline MGTL & -1.0717 & 10.74 & -10.79 \\
\hline
\end{tabular}

\section{Subjective Data Analyses}

Seventy-seven people participated during the study, one of whom did not complete the test. Results are presented for the 76 subjects who completed the test. The central tendency parameter used to characterize the magnitude estimation scores is the geometric mean of the magnitude estimates for each stimulus. It is customary (Stevens, 1956) to use geometric averaging with the magnitude estimation method since the distribution of the logarithms of the magnitude estimates is approximately normal. Subjective loudness is a power function of the physical intensity of a sound. Such a power function is linear when expressed in terms of the logarithms of the subjective loudness and sound pressure level. As
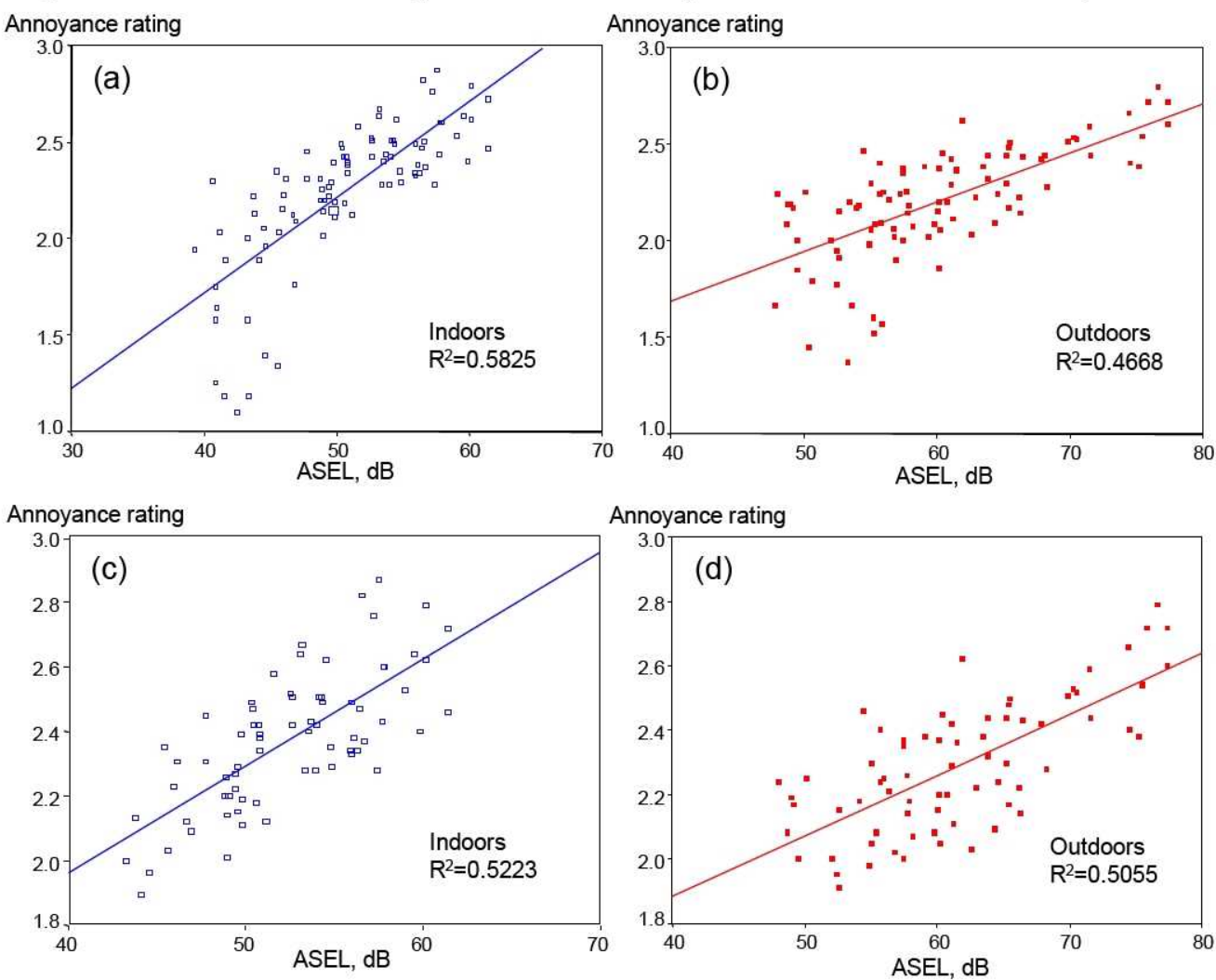

Figure 10 - Annoyance response plotted against ASEL: (a) results for all booms, indoor measurements; (b) results for all booms, outdoor measurements; (c) results for booms with SNR $>5 \mathrm{~dB}$, indoor measurements; (d) results for booms with SNR $>5 \mathrm{~dB}$, outdoor measurements. 
the acoustical metrics were found to be highly correlated, data is generally presented using ASEL for the primary $\mathrm{N}$-wave.

The mean scores for the 91 test booms, plotted against ASEL, are shown in figure 10 for both indoor (figure 10(a)) and outdoor (figure 10(b)) measurements. It is apparent, especially in the indoor results, that booms receiving the lowest ratings do not have correspondingly low sound levels. Close examination showed that these low ratings occurred mainly on the first and second days. The system noise floor was adjusted for the indoor microphone channel to improve the acquisition signal to noise ratio after the first two days. Outdoors, the first day and, to a lesser extent, the second day were affected by wind noise. Thus both indoors and outdoors, the signal to noise ratio (SNR) was poor for the lower level booms on the first two days of the test. When data with poor SNR were rejected, as described above in Acoustical Analyses, the relationship between mean score and ASEL becomes more linear (see figures $10(\mathrm{c})$ and $10(\mathrm{~d}))$. These plots demonstrate the expected increase in reported annoyance as the ASEL of the boom increases.

Table 5 shows Pearsons correlation coefficients between the mean ratings and 11 metrics, for the outdoor and indoor listening conditions using data for the 71 booms with acceptable signal-to-noise ratio. All correlation coefficients are significant at the $\mathrm{p}<0.0001$ level. Results are given for outdoor ratings correlated with outdoor measurements, indoor ratings with indoor measurements, and indoor ratings with outdoor measurements. This final data set is of importance because community noise measurements are normally made outside.

Because the reference sound level was on average $2.2 \mathrm{~dB}$ higher outdoors than indoors (see Acoustical Measurements section above), the subjective ratings of the booms were adjusted to compensate for this difference. A linear regression of mean rating on metric level was calculated for each location, indoors and out. The regression coefficients were used to adjust the scores. The outdoor scores were raised by the equivalent of $1.1 \mathrm{~dB}$ and the indoor scores were reduced by $1.1 \mathrm{~dB}$. This change to the $\log (\mathrm{score})$ was approximately 0.05 , which is equivalent to a change in score, for example, from 100 to 110 . The effect can be seen in figure 11: figure 11(a) shows the mean of the log of the uncorrected results, plotted against ASEL for the indoor and outdoor results, and figure 11(b) shows the same data, using the corrected scores. Figures 11 (c) and (d) show the results for corrected scores plotted against PL and CSEL. More details of the correction procedure are given in Appendix F.

Table 5 - Correlations between subjective ratings and metric levels for outdoor and indoor listening.

\begin{tabular}{|l|l|l|l|}
\hline Subject location & Outdoors & Indoors & Indoors \\
\hline Measurement location & Outdoors & Indoors & Outdoors \\
\hline Pmax & 0.616 & 0.603 & 0.659 \\
\hline ASEL & 0.711 & 0.723 & 0.771 \\
\hline CSEL & 0.624 & 0.732 & 0.737 \\
\hline ZSEL & 0.617 & 0.614 & 0.629 \\
\hline LLZd & 0.663 & 0.708 & 0.780 \\
\hline LLZf & 0.655 & 0.705 & 0.776 \\
\hline PL & 0.685 & 0.729 & 0.786 \\
\hline PNL & 0.666 & 0.687 & 0.776 \\
\hline Mgstat & 0.663 & 0.710 & 0.796 \\
\hline MGTS & 0.672 & 0.683 & 0.788 \\
\hline MGTL & 0.660 & 0.682 & 0.798 \\
\hline
\end{tabular}



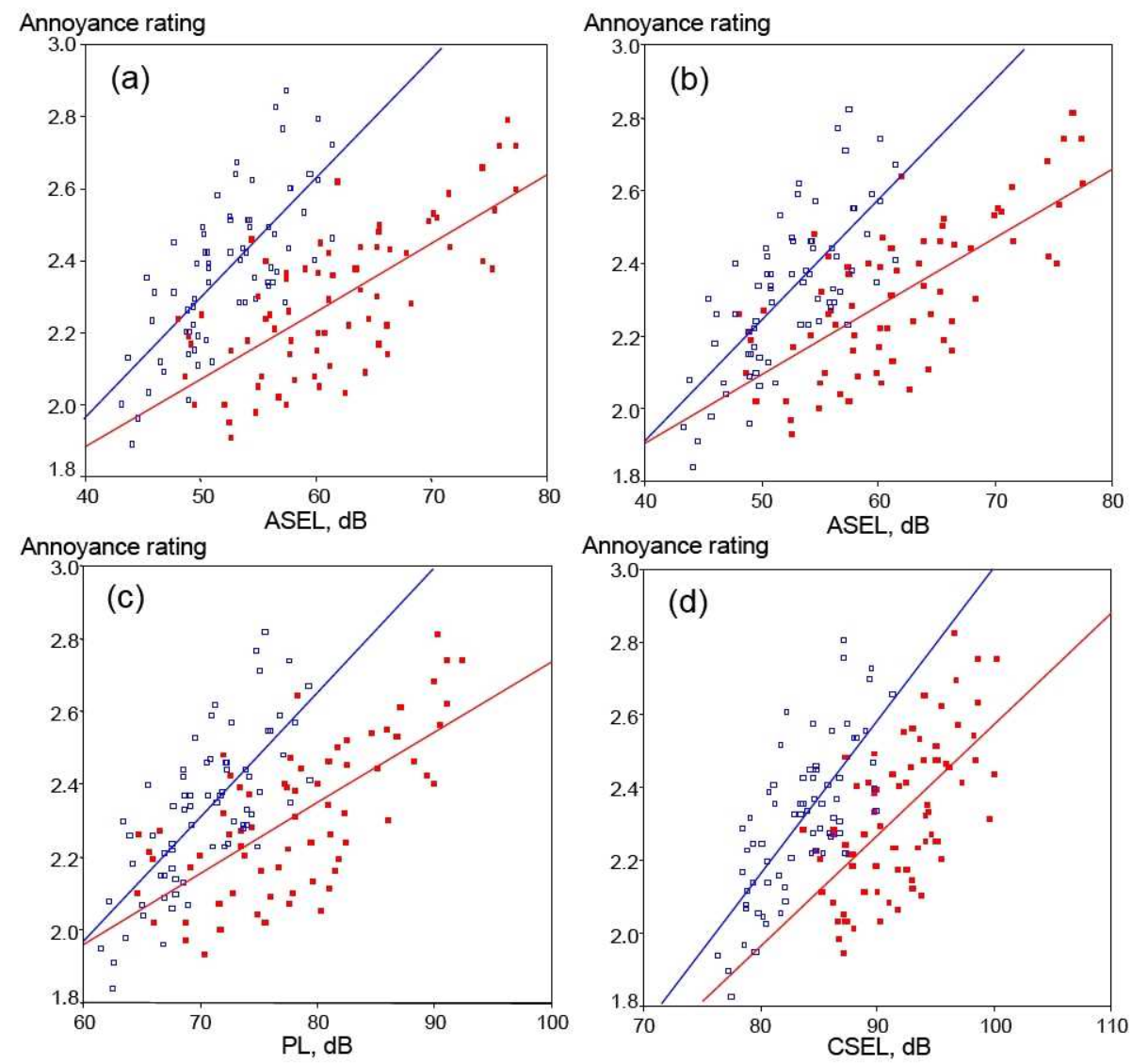

Figure 11 - Annoyance response plotted against metric level, results for booms with SNR > $5 \mathrm{~dB}$ : (a) uncorrected annoyance ratings versus ASEL; (b) annoyance ratings corrected for reference sound level error versus ASEL; (c) annoyance ratings corrected for reference sound level error versus PL; (d) annoyance ratings corrected for reference sound level error versus CSEL. — $\square$ inside results —

Indoor ratings of the sonic booms were compared to outdoor ratings (see figure 12) for the response data as measured (figure 12(a)) and as corrected for the indoor/outdoor reference level disparity (figure 12(b)). Also plotted is the line $\mathrm{Y}=\mathrm{X}$ for comparison. It is apparent that the responses are highly correlated (Pearson correlation coefficient $=0.4075, \mathrm{p}<0.001$ ) and, once corrected for the reference level error, lie close to the line $\mathrm{Y}=\mathrm{X}$, that is, the indoor ratings equal the outdoor ratings. As the attenuation due to the house structure reduces the indoor sound levels below the outdoor levels, the initial expectation would be that ratings would be lower indoors as well. This is evidently not the case.

Using the ratings corrected for the reference disparity using the appropriate metric data, and excluding data with metric levels contaminated by high noise levels, figures 13(a) and 13(b) show mean ratings for the two listening sites, indoors and outdoors, plotted against metrics computed from data recorded by microphones in the vicinity of the subjects ("at-ear" metric levels). ASEL and CSEL data are shown. It is evident that there is a separation between the regression lines: for both metrics, the indoor data lies above the outdoor responses, showing that for equal metric levels in the range of levels considered in this test, the indoor sound is judged more annoying than the outdoor. The same trend is evident for all the metrics examined. Figures 13 (c) and 13(d) show the same rating data plotted against the metric level as measured by the outdoor microphone. Thus, the ratings given by the subjects indoors are shown plotted against the levels measured outdoors. The data sets are seen to coincide, so that any particular boom receives the same rating whether it is heard indoors or outdoors. It would appear that the change in level caused by the boom's passage through the structure is almost entirely offset by the increase in annoyance reported by the indoor subjects. 

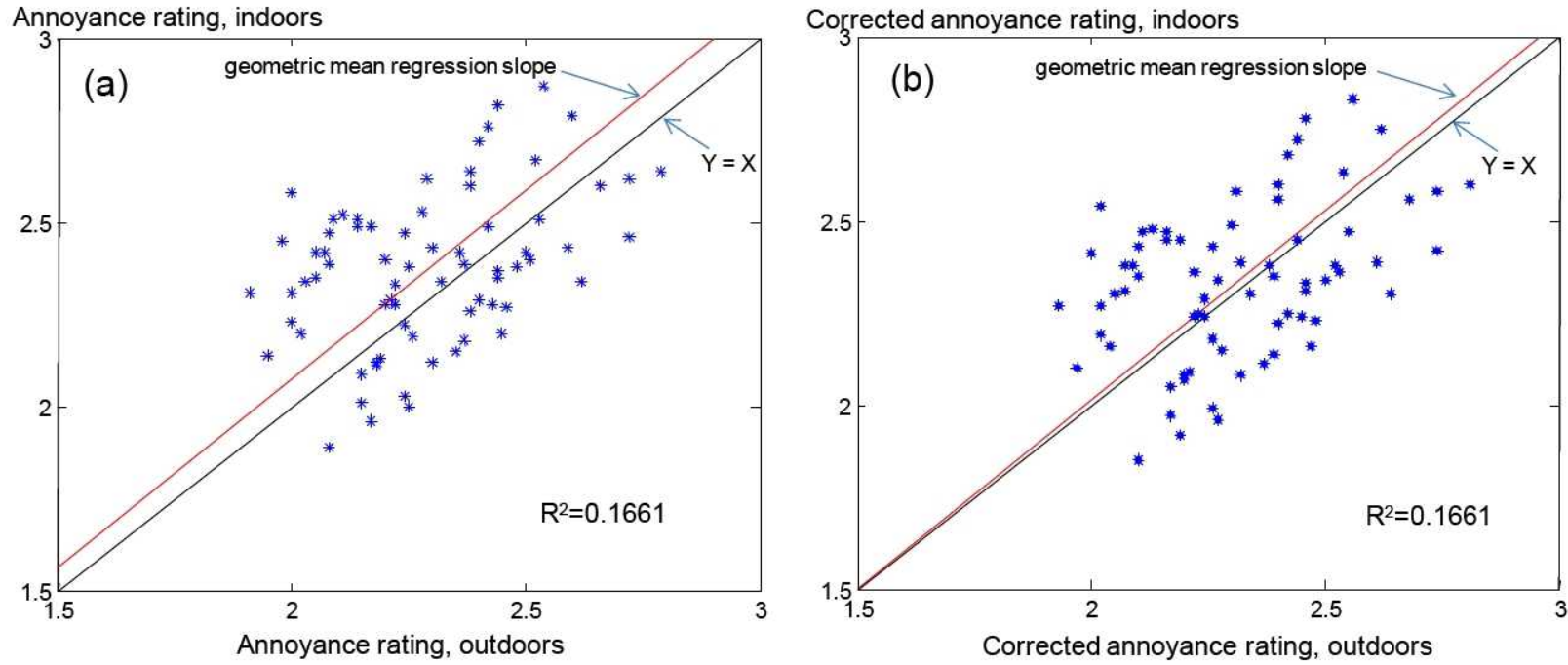

Figure 12 - Indoor versus outdoor ratings for booms with SNR > $5 \mathrm{~dB}$ : (a) ratings as measured;

(b) ratings corrected for reference noise level error.

\section{Questionnaire}

Each test day, after the test was completed, the subjects were asked to fill out a questionnaire, which is given in Appendix A, together with a summary of the responses. The first question was "Today you
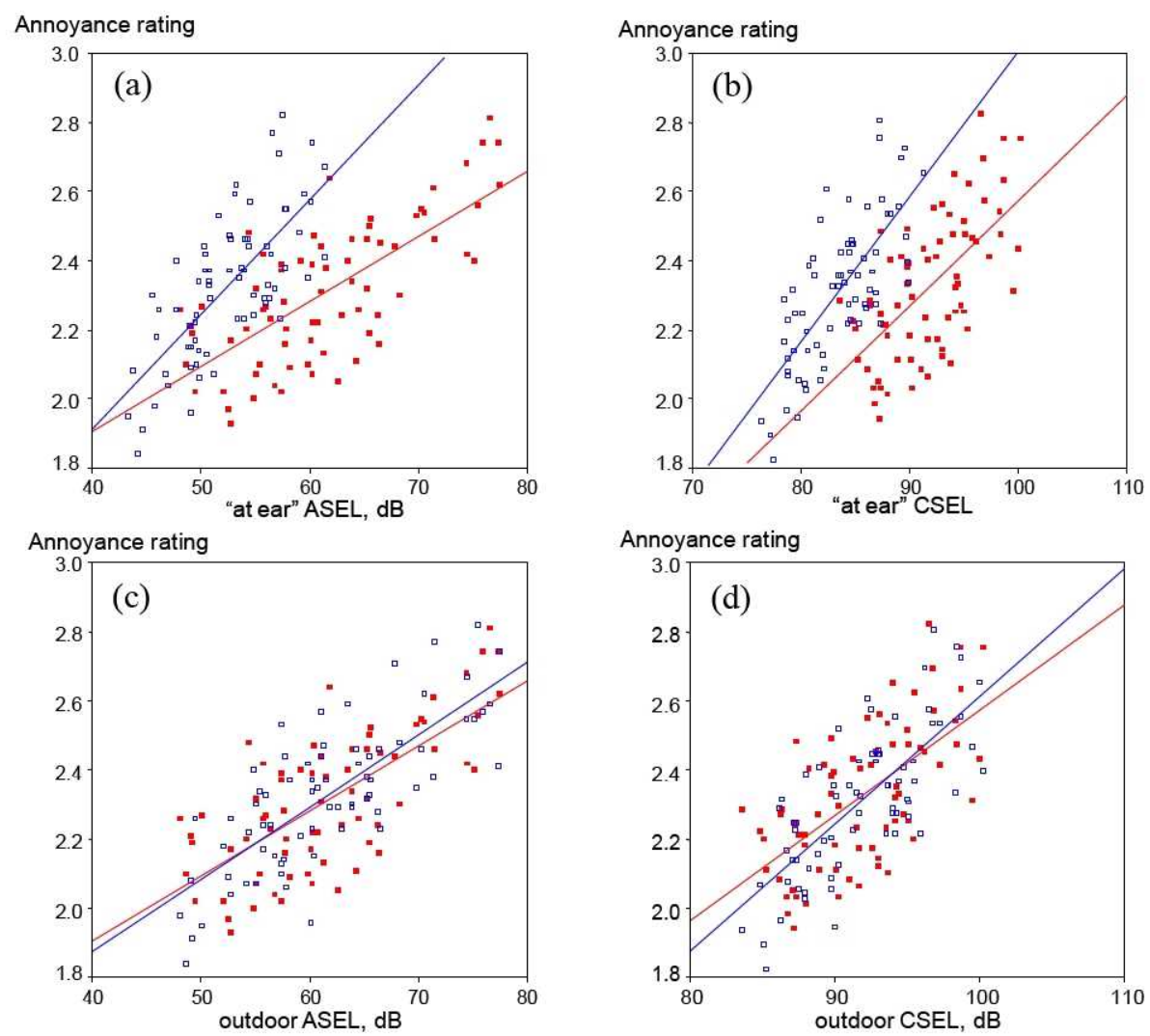

Figure 13 - Indoor and outdoor ratings corrected for reference error against metric level, for booms with SNR > $5 \mathrm{~dB}$ : (a) using ASEL as measured near the listening positions; (b) using CSEL as measured near the listening positions; (c) using ASEL as measured outdoors; (d) using CSEL as measured outdoors. 
heard sonic booms while you were inside the house and while you were outside. Thinking back, which were more annoying?" The responses clearly show greater annoyance inside (48 respondents, 63.2\%) compared to outside (11 respondents, $14.5 \%$ ) or equal (17 respondents, $22.4 \%$ ). This result is unlikely to have arisen by chance (using the binomial distribution, the probability of at least 48 of 76 respondents finding booms heard inside were most annoying is $\mathrm{P}(\mathrm{x}>=48 ; 76,0.333)=2.407 \mathrm{e}-9$, calculated using $\mathrm{http} / /$ stattrek.com/Tables/binomial.aspx). Thus, it is extremely unlikely that subjects were answering this question at random. Most subjects reported rattle sounds and this caused some annoyance; a similar number of people reported annoyance caused by the house vibrating or shaking. More subjects reported startle from the booms heard indoors, and expressed somewhat greater annoyance. Anecdotal evidence from visitors to the test site and others present clearly showed that the booms heard indoors were considered much more annoying than the same booms heard outdoors.

\section{Discussion}

Average annoyance ratings of individual sonic booms, both indoors and outdoors, were highly correlated with measured noise levels. All of the commonly used noise metrics were highly correlated with each other and with the annoyance ratings, and thus all metrics had similar predictive ability both indoors and out. Indoor levels were typically 7 to $9 \mathrm{~dB}$ below those measured outdoors for metrics such as ASEL, PL and CSEL.

The indoor annoyance ratings were highly correlated with the outdoor ones. On average the indoor and outdoor ratings of each boom were the same, indicating that indoor and outdoor annoyance are the same for this study. This is in contrast to previous findings that indicated indoor annoyance to be somewhat higher than outdoor annoyance.

Previous studies concluded that the presence of rattle causes an increase in annoyance of between 0 and $20 \mathrm{~dB}$. Since this study did not attempt to control the presence of rattle no quantitative conclusions can be drawn. It should be noted, however, that the test house was very "loose" and had highly pronounced rattling of doors and windows. The fact that the indoor and outdoor ratings were the same suggests that any penalty due to rattle is quite small.

There is an inconsistency in the results from the post-test questionnaire and the ratings of the individual booms. In contrast to the ratings of the individual booms, the post-test questionnaire results indicate that the test subjects found the indoor sonic booms to be more annoying than the outdoor ones. There are several possible explanations for this inconsistency. The method of magnitude estimation, with a constant reference sound, was deliberately chosen in order that the indoor and outdoor ratings would be directly comparable. Perhaps all sounds, including the reference sound, are more annoying indoors. This could be due to psychological factors such as expectations of indoor quiet, or acoustical factors such as differing ambient noise levels, reverberation, etc. If all sounds are more annoying indoors then the choice of the magnitude estimation technique was clearly inappropriate. Furthermore, the test methodology requires the test subjects to compare sonic booms with the reference sound. This may have had the effect that the subjects emphasized the acoustical attributes of the sonic booms and minimized other factors such as vibration and rattle. 


\section{References}

American National Standards Institute (1997): Specification for Sound Level Meters. ANSI S1.4-1983 (R1997), Acoustical Society of America, New York.

American National Standards Institute (2005): American National Standard Acoustical Terminology. ANSI S1.11994 (R2004), Acoustical Society of America, New York.

Borsky, P.N. (1965): Community Reactions to Sonic Booms in the Oklahoma City Area: Volume II: Data on community reactions and interpretations. National Opinion Research Center, AMRL-TR-65-37.

Borsky, P.N. (1972): Sonic Boom Exposure Effects II.4: Annoyance Reactions. J. Sound and Vibration vol 20, pp.527-530.

Cawthorn, J. M., Dempsey, T. K., and DeLoach, R (1978): Human response to aircraft-noise-induced building vibration. NASA CP-2052.

Fidell, S., Silvati, L., and Pearsons, K. (2002): Relative rates of growth of annoyance of impulsive and nonimpulsive noises. J. Acoust. Soc. Am., vol. 111, no.1, part 2, pp. 576-585.

Fields, James M. (1997): Reactions of Residents to Long-Term Sonic Boom Noise Environments. NASA CR201704.

Glasberg, B.R. and Moore, B.C.J. (2002): A Model of Loudness Applicable to Time-Varying Sounds. J. Audio Eng. Soc., vol. 50, no. 5, pp. 331-341 (as implemented by Andrew Marshall, Purdue University (personal communication, 2007))

Glasberg, B.R., and Moore, B.C.J. (2006): Prediction of absolute thresholds and equal-loudness contours using a modified loudness model. J. Acoust. Soc. Am., vol. 120, no. 2, pp. 585-588.

Guilford, J. P. (1954): Psychometric Methods. McGraw-Hill.

Haering, Jr., E. A., Smolka, J. W., Murray, J. E. and Plotkin, K. J. (2006): Flight Demonstration Of Low

Overpressure N-Wave Sonic Booms And Evanescent Waves. Innovations In Nonlinear Acoustics: ISNA17 - $17^{\text {th }}$

International Symposium on Nonlinear Acoustics including the International Sonic Boom Forum. AIP Conference Proceedings, vol. 838, pp. 647-650.

International Electrotechnical Commission (2002): Electroacoustics - Sound Level Meters; Part 1: Specifications. IEC 61672-1.

International Organization for Standards (1996): Method for Calculating Loudness Level (Method B). ISO R532.

Johnson, D.R.; and Robinson, D.W. (1967): The Subjective Evaluation of Sonic Bangs. Acustica, vol. 18, no. 5, pp. 241-258.

Johnson, D. R.; and Robinson, D. W. (1969): Procedure for Calculating the Loudness of Sonic Bangs. Acustica, vol. 21, no. 6, pp. 307-318.

Klos, J. and Buehrle, R. D. (2007): Vibro-Acoustic Response of Buildings Due to Sonic Boom Exposure: June 2006 Field Test. NASA TM-2007-214900, (available on line at http://ntrs.nasa.gov/archive/nasa/casi.ntrs.nasa.gov/20070031109_2007030401.pdf. Accessed Nov 30 2009)

Kryter, K. D., Johnson, P. J. and Young, J. R. (1968): Psychological Experiments on Sonic Booms Conducted at Edwards Air Force Base. Final Report, Contract AF49(638)-1758, Stanford Research Institute, Menlo Park, California. 
Leatherwood, J. D.; and Sullivan, B. M. (1993): Loudness and Annoyance Response to Simulated Outdoor and Indoor Sonic Boom. NASA TM-107756.

Leatherwood, J. D.; Sullivan, B. M.; Shepherd, K. P.; McCurdy, D. A.; Brown, S. A. (2002): A summary of recent NASA studies of human response to sonic booms.: J. Acoust. Soc. Am., vol. 111, no. 1, part. 2, pp. 586-598.

Locey, L. L., and Sparrow, V. W. (2007): Perceived Loudness Fluctuations in Low-Boom Signatures Due To Atmospheric Turbulence. 19th International Congress On Acoustics, Madrid, Paper NLA-08-010.

Maglieri, D. J., and Plotkin, K. J. (1991): Sonic Boom. Aeroacoustics of Flight Vehicles: Theory and Practice. Voume. 1: Noise Sources, Hubbard, H. H., ed., NASA Reference Publication 1258, Vol. 1, pp. 524-525.

McDaniel, Scott; Leatherwood, Jack D.; and Sullivan, Brenda M. (1992): Application of Magnitude Estimation Scaling to the Assessment of Human Subjective Loudness Response to Simulated Sonic Booms. NASA TM 107657 (available on line at http://ntrs.nasa.gov/archive/nasa/casi.ntrs.nasa.gov/19920024475_1992024475.pdf, Accessed Nov 30 2009).

Nixon, C, W., and Borsky, P. N. (1966): Effects of Sonic Boom on People: St. Louis, Missouri, 1961-1962. J. Acoust. Soc. Am., vol. 39, no.5, part 2, pp. S51-S58.

Paulus, E., and Zwicker, E. (1972): Programme zur automatischen Bestimmung der Lautheit aus Terzpegeln oder Frequenztgruppenpegeln. Acustica, vol. 27, pp. 253-266.

Pearsons, K. S. and Bennett, R. L. (1974): Handbook of Noise Metrics. NASA CR-2376 (available on line at http://ntrs.nasa.gov/archive/nasa/casi.ntrs.nasa.gov/19740015162_1974015162.pdf. Accessed Nov 30 2009).

Pearsons, K. S. and Kryter, K. D. (1964): Laboratory Tests of Subjective Reactions for Sonic Boom. NASA CR 187, (available on line at http://ntrs.nasa.gov/archive/nasa/casi.ntrs.nasa.gov/19650008276_1965008276.pdf. Accessed Nov 30 2009).

Pearsons, K. S., Tabachnick, B., Howe, R., Ahuja, K. K. and Stevens, J. C. (1993): A study of the effects of sonic boom waveform modification of annoyance. NASA CR-unnumbered (Contract NAS1-19061) (unpublished).

Schomer, P. D. and Averbuch, A. (1989): Indoor human response to blast sounds that generate rattles. J. Acoust. Soc. Am., vol. 86, no. 2, pp. 665-674.

Schomer, P. D. and Neathammer, R. D. (1987): The role of helicopter noise-induced vibration and rattle in human response. J. Acoust. Soc. Am., vol. 81, no. 4, pp. 966-975.

Schomer, P. D., Sias, J. W., and Maglieri, D. (1997): A comparative study of human response, indoors, to blast noise and sonic booms. Noise Contr Eng J., vol. 45, no. 4, pp. 169-182.

Schomer, P. D., Wagner, L. R., Benson, L. J., Buchta, E., Hirsch, K-W., and Krahé, D. (1994): Human and Community Response to Military Noise. Noise Contr Eng J., vol. 42, no. 2, pp. 71-84.

Shepherd, Kevin P.; and Sullivan, Brenda M. (1991): A Loudness Calculation Procedure applied to Shaped Sonic Booms: NASA TP-3134 (available on line at http://ntrs.nasa.gov/archive/nasa/casi.ntrs.nasa.gov/19920002547_1992002547.pdf. Accessed Nov 30 2009).

SPSS Inc. (1975): Statistical Package for the Social Science. McGraw-Hill (2 ${ }^{\text {nd }}$ edition), pp. 381-383.

SPSS Inc. (2002): SPSS for Windows 11.5C

Stevens, S. S. (1956): The Direct Estimation of Sensory Magnitudes: Loudness. Am. J. of Psychology, vol. 69, pp. $1-25$.

Stevens, S.S. (1972): Perceived Level of Noise by Mark VII and Decibels(E). J. Acoust. Soc. Am., vol. 54, no. 2 part 2, pp. 575-601. 
Stevens, S.S. (1975): Psychophysics, John Wiley \& Sons, pp. 269-270.

Zwicker, E., Fastl, H., Widmann, U., Kurakata, K., Kowano, S. and Namba, S. (1991): Program for calculating loudness according to DIN 45631 (ISO 532B). J. Acoust. Soc Jpn. (E), vol. 12, no. 1, pp. 39-67. 


\section{Appendix A.}

\section{Post-test Questionnaire}

Subject Number :

Date:

Sonic Boom Questionnaire

1) Today you heard sonic booms while you were inside the house and while you were outside.

Thinking back, which were more annoying?

Circle one of the following:

\begin{tabular}{|l|l|l|}
\hline The booms heard inside & The booms heard outside & About the same
\end{tabular}

2) While you were outdoors, did any of the booms startle you?

\begin{tabular}{|l|l|l|}
\hline Yes & No & Don't know \\
\hline
\end{tabular}

And how annoyed did this make you feel?

\begin{tabular}{|l|l|l|l|l|}
\hline Not at all & A little & Moderately & Very & Don't know \\
\hline
\end{tabular}

3) While you were indoors, did any of the booms startle you?

\begin{tabular}{|l|l|l|}
\hline Yes & No & Don't know \\
\hline
\end{tabular}

And how annoyed did this make you feel?

\begin{tabular}{|l|l|l|l|l|}
\hline Not at all & A little & Moderately & Very & Don't know \\
\hline
\end{tabular}

4) Did any of the booms make the house vibrate or shake?

\begin{tabular}{|l|l|l|}
\hline Yes & No & Don't know \\
\hline
\end{tabular}

And how annoyed did this make you feel?

\begin{tabular}{|l|l|l|l|l|}
\hline Not at all & A little & Moderately & Very & Don't know \\
\hline
\end{tabular}


5) Did any of the booms make the windows or other objects rattle?

\begin{tabular}{|l|l|l|}
\hline Yes & No & Don't know \\
\hline
\end{tabular}

And how annoyed did this make you feel?

\begin{tabular}{|l|l|l|l|l|}
\hline Not at all & A little & Moderately & Very & Don't know \\
\hline
\end{tabular}

6) Have you heard sonic booms before today?

\begin{tabular}{|l|l|l|}
\hline Yes & No & Don't know \\
\hline
\end{tabular}

7) Do you hear sonic booms where you currently live?

\begin{tabular}{|l|l|l|}
\hline Yes & No & Don't know \\
\hline
\end{tabular}

8) How much are you annoyed by the sonic booms that you hear at home?

\begin{tabular}{|l|l|l|l|l|}
\hline Not at all & A little & Moderately & Very & Don't know \\
\hline
\end{tabular}

9) Do you work in an Aerospace-related industry?

\begin{tabular}{|l|l|l|}
\hline Yes & No & Don't know \\
\hline
\end{tabular}

Questionnaire results

1) Today you heard sonic booms while you were inside the house and while you were outside. Thinking back, which were more annoying?

\begin{tabular}{|ll|l|l|}
\hline & Frequency & $\begin{array}{l}\text { Percent of } \\
\text { valid } \\
\text { responses }\end{array}$ \\
\hline Valid & outside & 11 & 14.5 \\
& about the same & 17 & 22.4 \\
& inside & 48 & 63.2 \\
& Total & 76 & 100.0 \\
\hline
\end{tabular}

2) While you were outdoors, did any of the booms startle you?

\begin{tabular}{|ll|l|l|}
\hline & Frequency & $\begin{array}{l}\text { Percent of } \\
\text { valid } \\
\text { responses }\end{array}$ \\
\hline Valid & don't know & 1 & 1.3 \\
& no & 41 & 53.9 \\
& yes & 34 & 44.7 \\
& Total & 76 & 100.0 \\
\hline
\end{tabular}


2a And how annoyed did this make you feel?

\begin{tabular}{|ll|l|l|}
\hline & Frequency & $\begin{array}{l}\text { Percent of } \\
\text { valid } \\
\text { responses }\end{array}$ \\
\hline Valid & not at all & 28 & 36.8 \\
& a little & 25 & 32.9 \\
& moderately & 16 & 21.1 \\
& very & 7 & 9.2 \\
& Total & 76 & 100.0 \\
\hline
\end{tabular}

3 While you were indoors, did any of the booms startle you?

\begin{tabular}{|ll|l|l|}
\hline & Frequency & $\begin{array}{l}\text { Percent of } \\
\text { valid } \\
\text { responses }\end{array}$ \\
\hline Valid & no & 27 & 35.5 \\
& yes & 49 & 64.5 \\
& Total & 76 & 100.0 \\
\hline
\end{tabular}

3a And how annoyed did this make you feel?

\begin{tabular}{|ll|l|l|}
\hline & Frequency & $\begin{array}{l}\text { Percent of } \\
\text { valid } \\
\text { responses }\end{array}$ \\
\hline Valid & not at all & 20 & 26.3 \\
& a little & 19 & 25.0 \\
& moderately & 22 & 28.9 \\
& very & 15 & 19.7 \\
& Total & 76 & 100.0 \\
\hline
\end{tabular}

4 Did any of the booms make the house vibrate or shake?

\begin{tabular}{|ll|l|l|}
\hline & Frequency & $\begin{array}{l}\text { Percent of } \\
\text { valid } \\
\text { responses }\end{array}$ \\
\hline Valid & don't know & 2 & 2.6 \\
& no & 9 & 11.8 \\
& yes & 65 & 85.5 \\
& Total & 76 & 100.0 \\
\hline
\end{tabular}

4a And how annoyed did this make you feel?

\begin{tabular}{|ll|l|l|}
\hline & Frequency & $\begin{array}{l}\text { Percent of } \\
\text { valid } \\
\text { responses }\end{array}$ \\
\hline Valid & not at all & 22 & 29.3 \\
& a little & 19 & 25.3 \\
& moderately & 14 & 18.7 \\
& a little/moderately & 1 & 1.3 \\
& very & 19 & 25.3 \\
& Total & 75 & 100.0 \\
Missing & & 1 & \\
Total & & 76 & \\
\hline
\end{tabular}


5 Did any of the booms make the windows or other objects rattle?

\begin{tabular}{|ll|l|l|}
\hline & Frequency & $\begin{array}{l}\text { Percent of } \\
\text { valid } \\
\text { responses }\end{array}$ \\
\hline Valid & don't know & 4 & 5.3 \\
& no & 6 & 8.0 \\
& yes & 65 & 86.7 \\
Missing & Total & 75 & 100.0 \\
Total & & 1 & \\
\hline
\end{tabular}

5a And how annoyed did this make you feel?

\begin{tabular}{|ll|l|l|}
\hline & & Frequency & $\begin{array}{l}\text { Percent of } \\
\text { valid } \\
\text { responses }\end{array}$ \\
\hline Valid & not at all & 18 & 24.3 \\
& a little & 24 & 32.4 \\
& moderately & 13 & 17.6 \\
& very & 19 & 25.7 \\
& Total & 74 & 100.0 \\
Missing & & 2 & \\
Total & & 76 & \\
\hline
\end{tabular}

6 Have you heard sonic booms before today?

\begin{tabular}{|ll|l|l|}
\hline & & Frequency & $\begin{array}{l}\text { Percent of } \\
\text { valid } \\
\text { responses }\end{array}$ \\
\hline Valid & no & 5 & 6.7 \\
& yes & 70 & 93.3 \\
Total & 75 & 100.0 \\
Missing & & 1 & \\
Total & 76 & \\
\hline
\end{tabular}

7 Do you hear sonic booms where you currently live?

\begin{tabular}{|ll|l|l|}
\hline & Frequency & $\begin{array}{l}\text { Percent of } \\
\text { valid } \\
\text { responses }\end{array}$ \\
\hline Valid & don't know & 1 & 1.3 \\
& no & 12 & 16.0 \\
& yes & 62 & 82.7 \\
& Total & 75 & 100.0 \\
Missing & & 1 & \\
Total & & 76 & \\
\hline
\end{tabular}


How much are you annoyed by the sonic booms that you hear at home?

\begin{tabular}{|ll|l|l|}
\hline & & Frequency & $\begin{array}{l}\text { Percent of } \\
\text { valid } \\
\text { responses }\end{array}$ \\
\hline Valid & don't know & 0 & 0.0 \\
& not at all & 25 & 34.2 \\
& a little & 20 & 27.4 \\
& moderately & 19 & 26.0 \\
& very & 9 & 12.3 \\
Missing & Total & 73 & 100.0 \\
Total & & 3 & \\
\hline
\end{tabular}

9 Do you work in an Aerospace-related industry?

\begin{tabular}{|ll|l|l|}
\hline & Frequency & $\begin{array}{l}\text { Percent of } \\
\text { valid } \\
\text { responses }\end{array}$ \\
\hline Valid & No & 72 & 96.0 \\
& Yes & 2 & 2.7 \\
& Yes(retired) & 1 & 1.3 \\
Missing & Total & 75 & 100.0 \\
Total & & 1 & \\
\hline
\end{tabular}




\section{Appendix B.}

\section{Pilot Study}

In order to determine whether people would consistently rate sounds under level and timing constraints of the main test, a pilot study was conducted a NASA Langley Research Center in the Exterior Effects room, using the same synthesized test stimuli and reference stimulus as were to be used in the main test. The synthesized test stimuli and the reference stimulus were played over the same loudspeaker system positioned close behind the subjects' heads as was planned for the field test (see figure B-1) at nominal levels of 45, 50,55, and $60 \mathrm{~dB}$ ASEL. To simulate the real booms, synthesized booms were played over eight overhead loudspeakers. Some of the synthesized booms representing the "indoor" stimuli were filtered to simulate the high frequency energy loss expected inside a house. One was not filtered, so it was the same as one of the "outdoor" booms, though played at different levels. The range of "outdoor" boom ASEL levels was 50 to $65 \mathrm{~dB}$; the "indoor" booms ranged from 40 to $55 \mathrm{~dB}$. The reference stimulus was presented at $52.5 \mathrm{~dB}$ ASEL.

Twenty eight subjects (19 female and 9 male, with ages ranging from 18 to 68) completed the pilot study. Subjects participated in groups of 7, each group hearing two sessions, one "indoor" and one "outdoor". Only 7 subjects were tested at one time, because of the need for consistency in the playback levels of the booms from the overhead speakers. The order of presentation of simulated "indoor" and "outdoor" sessions was reversed on half of the test days. The timing of test stimuli was that anticipated in the field test, but the interval between the two sessions was only about 20 minutes.

The results demonstrated that the long interval between events did not cause problems for the subjects; the ratings for the boom played in both indoor and outdoor sessions aligned between sessions. No difficulty was found in using a noise as the reference for judging impulse sounds. As expected, no effect was found from having a reference of $52.5 \mathrm{~dB}$ and a test stimulus range of 40 to $60 \mathrm{~dB}$ for the indoor session, as opposed to having a reference of $52.5 \mathrm{~dB}$ and a test stimulus range of 45 to $65 \mathrm{~dB}$ for the outdoor session.

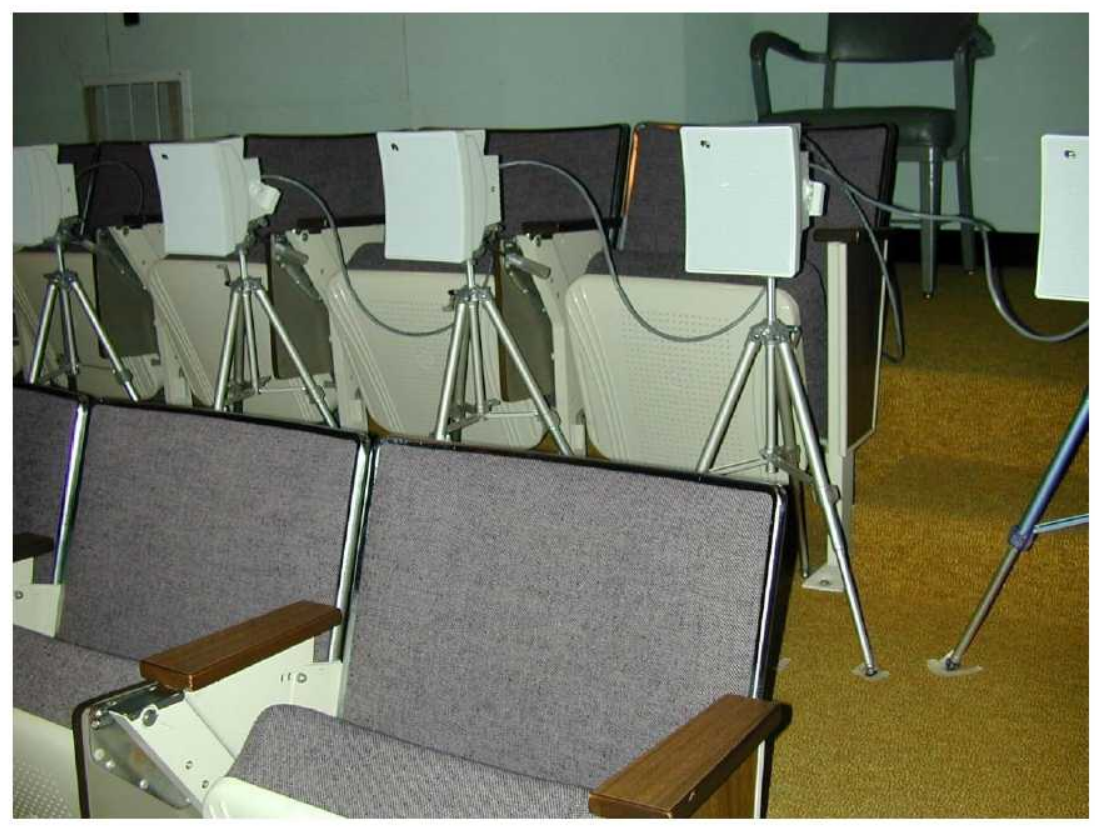

Figure B-1 - pilot study seating and speaker locations. 


\section{Appendix C.}

\section{Test Instructions}

Hello and welcome. We would like to explain something about the test for which we would like your help. You are going to hear various sounds and we want you to tell us just how annoying you think they are. We want to you write down your scores on the sheet provided. We are interested in your personal judgment: only you can tell us how annoying these sounds are to you. There will be two test sessions. Before the test sessions we will have a practice session.

Today, we would like to explain the way we want you to make your judgments of the sounds you hear.

During a test session you will hear a series of sounds. Some of the sounds will come from loudspeakers and some will come from other places. The first sound that you hear will be the word "reference" which will be followed by the REFERENCE sound. It sounds something like this:

Other sounds will be judged relative to this REFERENCE sound. To help you keep track, the REFERENCE sound will always be preceded by the word "reference". The reference sound will not change during the test session. Your task will be to tell us just how annoying each of the other sounds is as compared to the reference sound. After each sound that we would like you to score you will hear a voice asking you to judge the sound you just heard like this:

Other sounds may occur that are not a part of the test, and we ask you please to ignore these.

You will be given a rating sheet which will contain a series of lines, one for each sound we will ask you to judge:

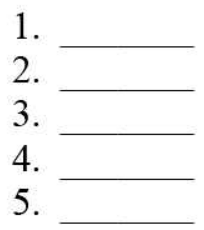

Here's the scoring process: The word "reference" will indicate that the sound which follows is the reference sound. Please listen to it carefully because you will compare the other sounds to it. For this purpose the reference sound will be assigned an annoyance value of 100 . Thus you do not score the reference sound because it will always equal 100 . The reference sound will be played more than once, but it will always be preceded by the word "reference".

At some point after you hear the reference sound, you will hear a COMPARISON sound. Each comparison sound is followed by the voice asking you to judge the sound you just heard. After listening to the comparison sound you should decide just how annoying you think it is relative to the reference sound and assign it a number accordingly. You will then enter this number on the appropriate line of the scoring sheet. For example, if you feel the comparison sound is three times more annoying than the reference sound then you would give it a score of 300 . If you think the comparison sound is only onefourth as annoying as the reference you would give it a score of 25. You may choose any number you wish as long as it faithfully represents your impression of the relative annoyance of the comparison and reference sounds.

For example, here is a reference and a comparison sound:

If you found the comparison sound somewhat more than twice as annoying as the reference, you would give it a score of more than 200; perhaps you would give it 245 or 253 . 
Here is another pair of reference and comparison sounds:

If you found the comparison sound a little less annoying than the reference, you would give it a score of just under 100, say 87 or 92 .

After a while you will hear the word "reference" again which will be followed by the reference sound.

Again, the reference sound may be played more than once, but it will always be preceded by the word "reference". After another interval of silence, you will hear another comparison sound for you to judge. The pattern of reference sounds and comparison sounds will be repeated until the session is over. The interval between sounds will vary but the reference sound is always preceded by the word "reference" and the comparison sound is always followed by the voice asking you to judge. Remember! There are no right or wrong answers. We are interested only in how annoying the sounds seem to you. You may use any number you like as long as it represents your feelings about the sound you heard. If you didn't hear a sound, please put down zero. 


\section{Appendix D.}

\section{Response Sheet}

Subject Number:

Date:

Test Name:

Session Name:

Please tell us how annoying each sound is compared to the reference sound.

Remember, the reference sound is scored 100.

Put 0 if you didn't hear any sound.

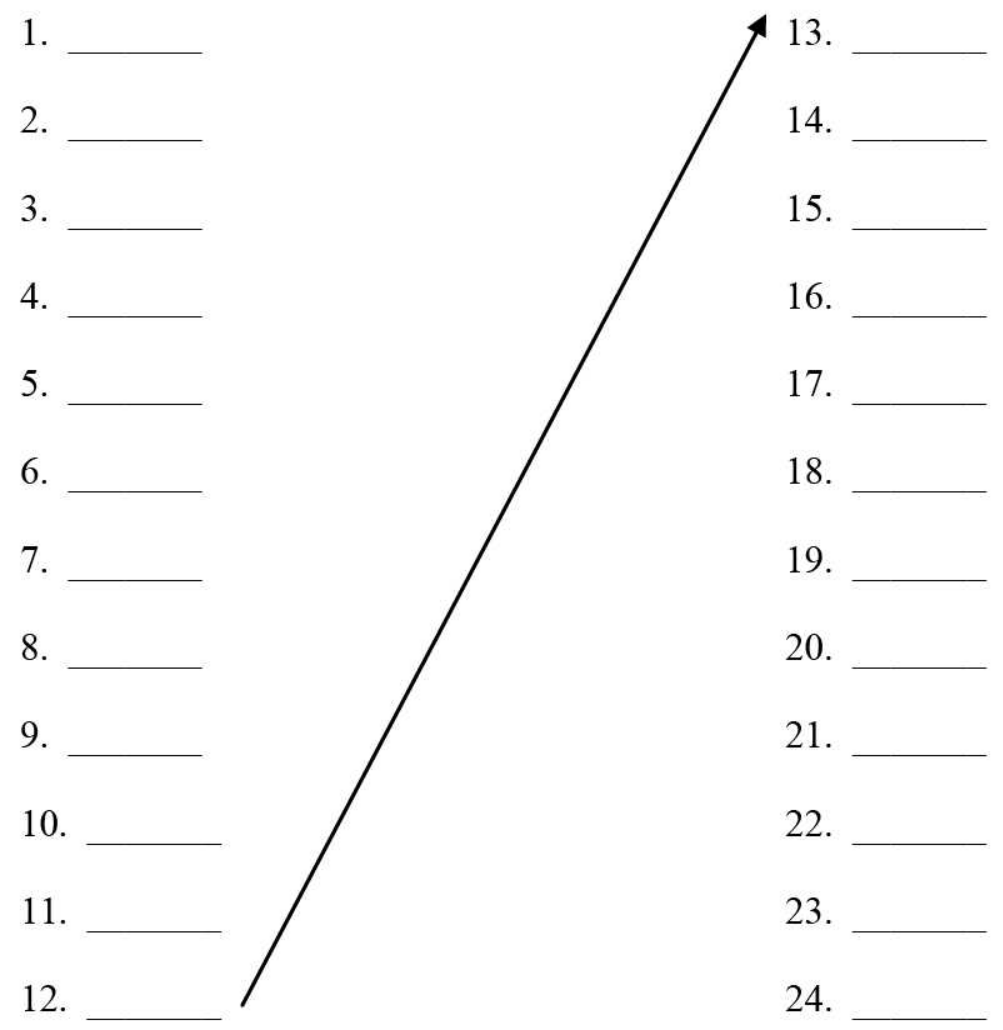




\section{Appendix E.}

\section{Metric Correlations}

Metrics calculated were:

maximum overpressure (Pmax)

sound exposure level with different weightings:

A-weighted (ASEL)

C-weighted (CSEL)

Zero weighted (unweighted) (ZSEL)

metrics based on $1 / 3$ octave analyses:

loudness level using Zwicker's method

diffuse incidence (LLZd)

frontal incidence (LLZf)

perceived level using Steven's Mk VII method (PL)

perceived noise level (PNL)

Glasburg and Moore stationary loudness level (MGstat)

Maximum Glasburg and Moore time-varying loudness level

short-term (MGTS)

long-term (MGTL)

SEL measures were calculated using the standard 1-s normalization time. LLZ, PL, PNL were calculated based on the procedure defined by Johnson and Robinson (1969; see also Shepherd and Sullivan (1991)) which uses a 70-ms normalization time.

Outdoor background noise included wind in leaves, birds singing, distant construction noise from elsewhere in the neighborhood, and, infrequently, passing cars and other aircraft. Indoors there was little background noise as the air-conditioning unit was turned off during the test sessions, as was the refrigerator in the kitchen. However, instrumentation noise on the indoor microphone channels was reduced on the final two days of testing compared to the first two days of testing, because the gain settings were optimized after the first two days. Thus, interior background levels were higher on the first two days of testing than on the final two days. The effects of the noise were to some extent ameliorated by omitting data which had a low estimated signal to noise ratio. Metrics were calculated for a sample of noise immediately preceding each boom event; if the metric level of the noise was within $5 \mathrm{~dB}$ of the level of the boom event, the response data was discarded for that particular boom event.

The following tables show the Pearson's correlation coefficients calculated using SPSS for Windows 11.5 (C) (2002). Some of the metric data is plotted in figure E-1. 
Correlations between metrics calculated for the outdoor microphone data

\begin{tabular}{|l|l|l|l|l|l|l|l|l|l|l|l|}
\hline & Pmax & ASEL & CSEL & ZSEL & LLZd & LLZf & PL & PNL & Mgstat & MGTS & MGTL \\
\hline Pmax & 1 & 0.839 & 0.942 & .891 & 0.880 & 0.882 & 0.833 & 0.788 & 0.704 & 0.726 & 0.698 \\
ASEL & 0.839 & 1 & 0.909 & 0.816 & 0.945 & 0.939 & 0.993 & 0.976 & 0.941 & 0.952 & 0.934 \\
CSEL & 0.942 & 0.909 & 1 & 0.865 & 0.953 & 0.957 & 0.920 & 0.888 & 0.786 & 0.803 & 0.778 \\
ZSEL & 0.891 & 0.816 & 0.865 & 1 & 0.838 & 0.839 & 0.804 & 0.764 & 0.734 & 0.745 & 0.729 \\
LLZd & 0.880 & 0.945 & 0.953 & 0.838 & 1 & 0.999 & 0.955 & 0.926 & 0.884 & 0.896 & 0.881 \\
LLZf & 0.882 & 0.939 & 0.957 & 0.839 & 0.999 & 1 & 0.951 & 0.923 & 0.873 & 0.886 & 0.870 \\
PL & 0.833 & 0.993 & 0.920 & 0.804 & 0.955 & 0.951 & 1 & 0.987 & 0.946 & 0.953 & 0.937 \\
PNL & 0.788 & 0.976 & 0.888 & 0.764 & 0.926 & 0.923 & 0.987 & 1 & 0.927 & 0.933 & 0.916 \\
Mgstat & 0.704 & 0.941 & 0.786 & 0.734 & 0.884 & 0.873 & 0.946 & 0.927 & 1 & 0.991 & 0.994 \\
MGTS & 0.726 & 0.952 & 0.803 & 0.745 & 0.896 & 0.886 & 0.953 & 0.933 & 0.991 & 1 & 0.995 \\
MGTL & 0.698 & 0.934 & 0.778 & 0.729 & 0.881 & 0.870 & 0.937 & 0.916 & 0.994 & 0.995 & 1 \\
\hline
\end{tabular}

Correlations are all significant at the 0.0001 level (2-tailed).

Correlations between metrics calculated for the indoor microphone data

\begin{tabular}{|l|l|l|l|l|l|l|l|l|l|l|l|}
\hline & Pmax & ASEL & CSEL & ZSEL & LLZd & LLZf & PL & PNL & Mgstat & MGTS & MGTL \\
\hline Pmax & 1 & 0.919 & 0.926 & 0.902 & 0.895 & 0.892 & 0.917 & 0.832 & 0.914 & 0.926 & 0.923 \\
ASEL & 0.919 & 1 & 0.954 & 0.877 & 0.948 & 0.944 & 0.999 & 0.955 & 0.991 & 0.973 & 0.976 \\
CSEL & 0.926 & 0.954 & 1 & 0.860 & 0.980 & 0.979 & 0.958 & 0.896 & 0.938 & 0.936 & 0.933 \\
ZSEL & 0.902 & 0.877 & 0.860 & 1 & 0.832 & 0.829 & 0.877 & 0.795 & 0.870 & 0.873 & 0.854 \\
LLZd & 0.895 & 0.948 & 0.980 & 0.832 & 1 & 1.000 & 0.950 & 0.897 & 0.932 & 0.925 & 0.922 \\
LLZf & 0.892 & 0.944 & 0.979 & 0.829 & 1.000 & 1 & 0.947 & 0.894 & 0.927 & 0.921 & 0.918 \\
PL & 0.917 & 0.999 & 0.958 & 0.877 & 0.950 & 0.947 & 1 & 0.956 & 0.990 & 0.971 & 0.974 \\
PNL & 0.832 & 0.955 & 0.896 & 0.795 & 0.897 & 0.894 & 0.956 & 1 & 0.923 & 0.884 & 0.899 \\
Mgstat & 0.914 & 0.991 & 0.938 & 0.870 & 0.932 & 0.927 & 0.990 & 0.923 & 1 & 0.986 & 0.987 \\
MGTS & 0.926 & 0.973 & 0.936 & 0.873 & 0.925 & 0.921 & 0.971 & 0.884 & 0.986 & 1 & 0.989 \\
MGTL & 0.923 & 0.976 & 0.933 & 0.854 & 0.922 & 0.918 & 0.974 & 0.899 & 0.987 & 0.989 & 1 \\
\hline
\end{tabular}

Correlations are all significant at the 0.0001 level (2-tailed). 
Correlations between indoor and outdoor metric levels

\begin{tabular}{|c|c|c|c|c|c|c|c|c|c|c|c|}
\hline indoor & $\begin{array}{l}\text { outdoor } \\
\text { Pmax }\end{array}$ & ASEL & CSEL & ZSEL & LLZd & LLZf & PL & PNL & Mgstat & MGTS & MGTL \\
\hline Pmax & 0.971 & 0.826 & 0.903 & 0.929 & 0.855 & 0.856 & 0.812 & 0.770 & 0.697 & 0.719 & 0.687 \\
\hline ASEL & 0.925 & 0.907 & 0.962 & 0.884 & 0.916 & 0.918 & 0.914 & 0.895 & 0.796 & 0.805 & 0.783 \\
\hline CSEL & 0.944 & 0.865 & 0.977 & 0.879 & 0.939 & 0.944 & 0.879 & 0.846 & 0.752 & 0.767 & 0.743 \\
\hline ZSEL & 0.863 & 0.849 & 0.855 & 0.934 & 0.840 & 0.840 & 0.837 & 0.801 & 0.769 & 0.784 & 0.766 \\
\hline LLZd & 0.908 & 0.857 & 0.959 & 0.846 & 0.944 & 0.951 & 0.876 & 0.851 & 0.751 & 0.767 & 0.742 \\
\hline LLZf & 0.906 & 0.853 & 0.958 & 0.843 & 0.944 & 0.950 & 0.873 & 0.848 & 0.747 & 0.763 & 0.738 \\
\hline PL & 0.927 & 0.911 & 0.968 & 0.882 & 0.921 & 0.923 & 0.919 & 0.899 & 0.801 & 0.810 & 0.787 \\
\hline PNL & 0.847 & 0.885 & 0.919 & 0.786 & 0.873 & 0.877 & 0.902 & 0.909 & 0.762 & 0.768 & 0.742 \\
\hline Mgstat & 0.913 & 0.877 & 0.939 & 0.882 & 0.886 & 0.888 & 0.881 & 0.860 & 0.771 & 0.777 & 0.756 \\
\hline MGTS & 0.918 & 0.843 & 0.928 & 0.897 & 0.865 & 0.867 & 0.844 & 0.813 & 0.728 & 0.739 & 0.716 \\
\hline MGTL & 0.919 & 0.839 & 0.929 & 0.885 & 0.858 & 0.860 & 0.840 & 0.814 & 0.713 & 0.724 & 0.700 \\
\hline
\end{tabular}

Correlations are all significant at the 0.0001 level (2-tailed).

Correlations between metrics for primary N-wave alone and both primary and secondary waveforms for outdoor data

\begin{tabular}{|c|c|c|c|c|c|c|c|c|c|c|c|}
\hline \multirow[b]{2}{*}{$\mathrm{N}$-wave } & \multicolumn{11}{|l|}{ both } \\
\hline & Pmax & ASEL & CSEL & ZSEL & LLZd & LLZf & PL & PNL & Mgstat & MGTS & MGTL \\
\hline Pmax & 1.000 & 0.839 & 0.943 & 0.883 & 0.881 & 0.883 & 0.839 & 0.793 & 0.683 & 0.726 & 0.698 \\
\hline ASEL & 0.840 & 0.994 & 0.894 & 0.795 & 0.939 & 0.933 & 0.989 & 0.971 & 0.924 & 0.950 & 0.933 \\
\hline CSEL & 0.943 & 0.900 & 0.986 & 0.850 & 0.943 & 0.948 & 0.915 & 0.883 & 0.755 & 0.801 & 0.777 \\
\hline ZSEL & 0.891 & 0.821 & 0.868 & 0.976 & 0.840 & 0.841 & 0.811 & 0.770 & 0.711 & 0.745 & 0.730 \\
\hline LLZd & 0.881 & 0.943 & 0.937 & 0.819 & 0.990 & 0.989 & 0.954 & 0.928 & 0.866 & 0.896 & 0.881 \\
\hline LLZf & 0.883 & 0.936 & 0.941 & 0.820 & 0.989 & 0.990 & 0.949 & 0.924 & 0.854 & 0.886 & 0.870 \\
\hline PL & 0.834 & 0.986 & 0.902 & 0.782 & 0.948 & 0.944 & 0.994 & 0.981 & 0.925 & 0.952 & 0.936 \\
\hline PNL & 0.789 & 0.966 & 0.870 & 0.744 & 0.919 & 0.916 & 0.978 & 0.992 & 0.906 & 0.931 & 0.915 \\
\hline Mgstat & 0.705 & 0.945 & 0.771 & 0.708 & 0.884 & 0.874 & 0.949 & 0.931 & 0.993 & 0.991 & 0.994 \\
\hline MGTS & 0.728 & 0.952 & 0.787 & 0.721 & 0.894 & 0.884 & 0.955 & 0.934 & 0.985 & 0.999 & 0.994 \\
\hline MGTL & 0.699 & 0.938 & 0.762 & 0.705 & 0.880 & 0.869 & 0.941 & 0.920 & 0.991 & 0.995 & 1.000 \\
\hline
\end{tabular}

Correlations are all significant at the 0.0001 level (2-tailed). 
Correlations between metrics for primary $\mathrm{N}$-wave and both waveforms for indoor data

\begin{tabular}{|l|l|l|l|l|l|l|l|l|l|l|l|}
\hline & both & & & & & \\
N-wave & Pmax & ASEL & CSEL & ZSEL & LLZd & LLZf & PL & PNL & Mgstat & MGTS & MGTL \\
\hline Pmax & 0.999 & 0.919 & 0.923 & 0.876 & 0.895 & 0.893 & 0.918 & 0.837 & 0.910 & 0.928 & 0.926 \\
ASEL & 0.916 & 0.980 & 0.932 & 0.831 & 0.939 & 0.936 & 0.981 & 0.937 & 0.976 & 0.966 & 0.970 \\
CSEL & 0.924 & 0.940 & 0.981 & 0.835 & 0.974 & 0.974 & 0.948 & 0.890 & 0.927 & 0.934 & 0.933 \\
ZSEL & 0.900 & 0.875 & 0.855 & 0.962 & 0.837 & 0.833 & 0.875 & 0.794 & 0.864 & 0.858 & 0.844 \\
LLZd & 0.892 & 0.925 & 0.952 & 0.798 & 0.986 & 0.986 & 0.932 & 0.883 & 0.913 & 0.918 & 0.917 \\
LLZf & 0.889 & 0.921 & 0.951 & 0.795 & 0.986 & 0.986 & 0.929 & 0.881 & 0.909 & 0.915 & 0.913 \\
PL & 0.915 & 0.980 & 0.937 & 0.832 & 0.942 & 0.939 & 0.983 & 0.939 & 0.976 & 0.965 & 0.969 \\
PNL & 0.832 & 0.937 & 0.873 & 0.752 & 0.894 & 0.891 & 0.941 & 0.978 & 0.923 & 0.892 & 0.903 \\
Mgstat & 0.911 & 0.967 & 0.917 & 0.819 & 0.919 & 0.915 & 0.968 & 0.903 & 0.974 & 0.974 & 0.978 \\
MGTS & 0.923 & 0.943 & 0.917 & 0.824 & 0.909 & 0.906 & 0.943 & 0.863 & 0.949 & 0.973 & 0.970 \\
MGTL & 0.920 & 0.948 & 0.914 & 0.808 & 0.905 & 0.902 & 0.948 & 0.877 & 0.954 & 0.965 & 0.983 \\
\hline
\end{tabular}

Correlations are all significant at the 0.0001 level (2-tailed).

Correlations between metrics calculated using data from ground-level microphone and 4-ft microphone.

\begin{tabular}{|l|l|l|l|l|l|l|l|l|}
\hline 4-ft & \multicolumn{2}{|l|}{ ground-level microphone } \\
microphone & Pmax & ASEL & CSEL & ZSEL & LLZd & LLZf & PL & PNL \\
\hline Pmax & 0.976 & 0.845 & 0.913 & 0.917 & 0.861 & 0.861 & 0.831 & 0.789 \\
ASEL & 0.840 & 0.992 & 0.917 & 0.802 & 0.945 & 0.940 & 0.991 & 0.978 \\
CSEL & 0.945 & 0.888 & 0.989 & 0.860 & 0.920 & 0.924 & 0.900 & 0.874 \\
ZSEL & 0.898 & 0.819 & 0.870 & 0.998 & 0.836 & 0.837 & 0.807 & 0.767 \\
LLZd & 0.854 & 0.951 & 0.943 & 0.805 & 0.970 & 0.970 & 0.968 & 0.958 \\
LLZf & 0.855 & 0.945 & 0.947 & 0.805 & 0.968 & 0.968 & 0.964 & 0.956 \\
PL & 0.844 & 0.982 & 0.931 & 0.801 & 0.952 & 0.949 & 0.993 & 0.984 \\
PNL & 0.796 & 0.949 & 0.904 & 0.755 & 0.919 & 0.918 & 0.966 & 0.976 \\
\hline
\end{tabular}

Correlations are all significant at the 0.0001 level (2-tailed). 

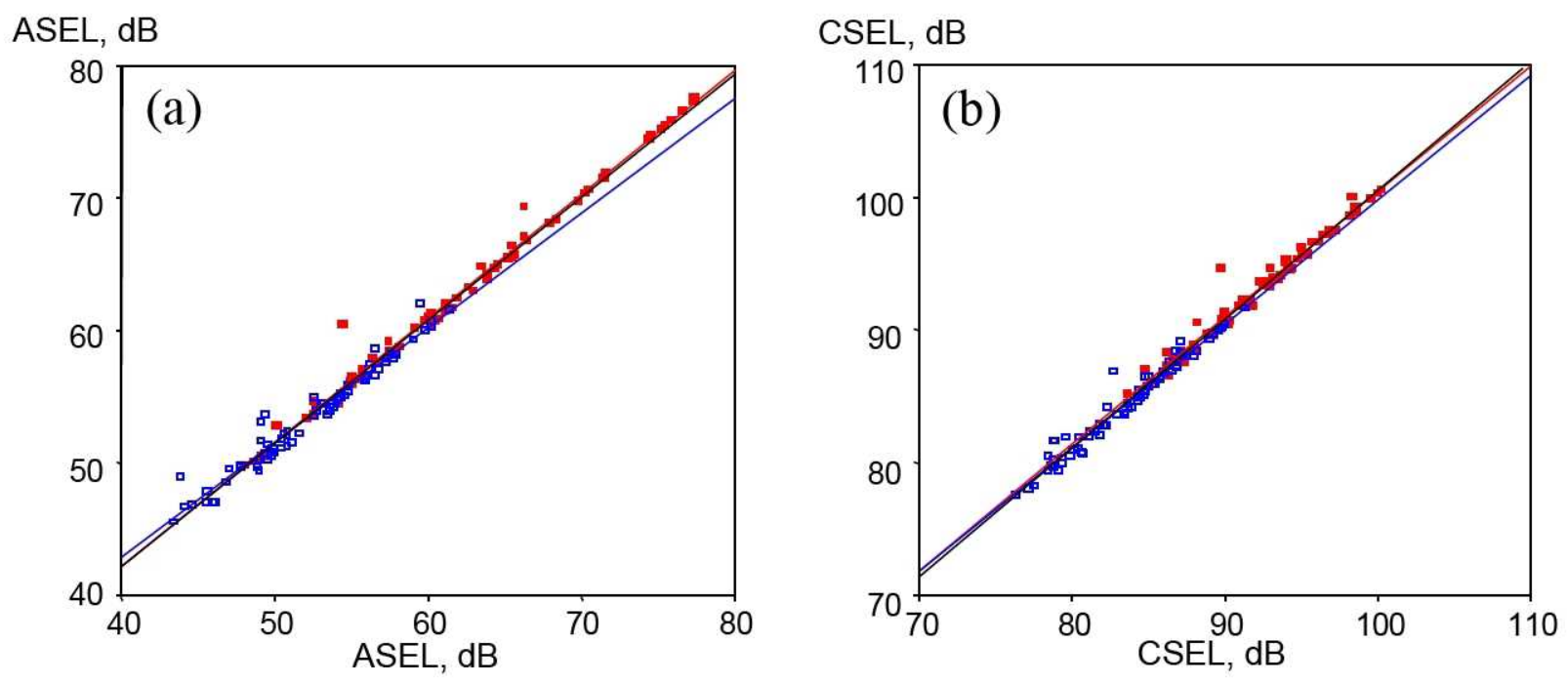

Figure E-1 - Metrics for both primary and secondary waves combined plotted against metric for primary N-wave only, for booms with SNR > 5 dB: (a) ASEL; (b) CSEL.

— inside results $\longrightarrow$ outside results $\quad \longrightarrow$ combined results 


\section{Appendix F.}

\section{Rating Corrections for Reference Level Error}

The test design called for the same reference sound to be played in both indoor and outdoor listening locations. The level chosen was $57 \mathrm{~dB}$ (ASEL). During the test, it was found that the indoor reference sound was lower than the outdoor level, with average levels of $56.9 \mathrm{~dB}$ inside and $59.1 \mathrm{~dB}$ outside. In order to compare the two data sets, i.e. indoor ratings and outdoor ratings, it was necessary to account for this discrepancy. As the reference levels were $2.2 \mathrm{~dB}$ apart, it was decided to correct both data sets to an intermediate level, so both data sets would be adjusted by $1.1 \mathrm{~dB}$.

In order to accomplish this, data for the real sonic booms were used. A linear regression line of mean rating on metric level was calculated for each location, indoors or out, and used to calculate the change in rating predicted by the metric for a boom $1.1 \mathrm{~dB}$ higher or lower. As the outdoor reference was higher than the average, then the test stimulus would appear relatively lower so the ratings would be low. Hence the ratings were increased by the change predicted from the regression line for the outdoor ratings on a specific metric. As the indoor reference was lower than the average, then the test stimulus would appear relatively higher so the ratings would be high. Thus the ratings were decreased by the change predicted from the regression line for the indoor ratings on a specific metric.

As an example of the procedure, consider the 71 booms with acceptable signal to noise ratio. Mean ratings are show in Fig 10(c and d) plotted against ASEL as measured near the subjects' locations. The regression lines plotted in those figures are given by:

Figure 10(c), mean rating on ASEL for the indoor data

$$
\text { rating }=0.6340+0.0332 * \mathrm{ASEL}
$$

Therefore a $1.1 \mathrm{~dB}$ change in metric level would result in a 0.0365 change in rating. Thus the indoor ratings were decreased by 0.0365 .

Figure 10(d), mean rating on ASEL for the outdoor data

$$
\text { rating }=1.1306+0.0188 * \mathrm{ASEL}
$$

Therefore a $1.1 \mathrm{~dB}$ change in metric level would result in a 0.0207 change in rating. Thus the outdoor ratings were increased by 0.0207 .

Similar corrections were performed for other metrics.

This change is less than a change of 0.05 to the mean logarithm of the scores, which is equivalent to a change in score, for example, from 100 to 110. 


\begin{tabular}{|c|c|c|c|c|}
\hline \multicolumn{4}{|c|}{ REPORT DOCUMENTATION PAGE } & $\begin{array}{l}\text { Form Approved } \\
\text { OMB No. 0704-0188 }\end{array}$ \\
\hline \multicolumn{5}{|c|}{ 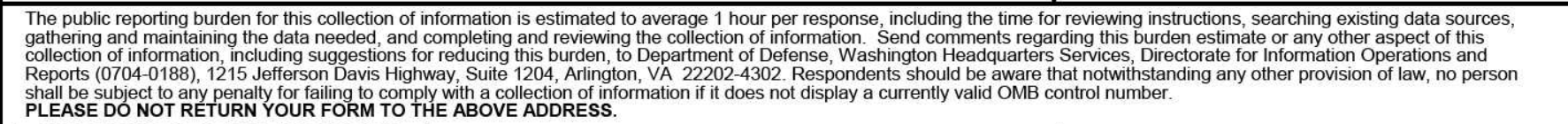 } \\
\hline \multicolumn{4}{|c|}{\begin{tabular}{|c|l} 
1. REPORT DATE (DD-MM-YYYY) & $\begin{array}{l}\text { 2. REPORT TYPE } \\
01-04-2010\end{array}$ \\
Technical Memorandum
\end{tabular}} & \begin{tabular}{l|l} 
3. DATES COVERED (From - To) \\
\end{tabular} \\
\hline \multirow{3}{*}{\multicolumn{4}{|c|}{$\begin{array}{l}\text { 4. TITLE AND SUBTITLE } \\
\text { Human Response to Low-Intensity Sonic Booms Heard Indoors and } \\
\text { Outdoors }\end{array}$}} & \multirow[t]{2}{*}{ 5a. CONTRACT NUMBER } \\
\hline & & & & \\
\hline & & & & 5c. PROGRAM ELEMENT NUMBER \\
\hline \multirow{4}{*}{\multicolumn{4}{|c|}{$\begin{array}{l}\text { 6. AUTHOR(S) } \\
\text { Sullivan, Brenda M.; Klos, Jacob; Buehrle, Ralph D.; McCurdy, David A; } \\
\text { Haering, Edward A., Jr. }\end{array}$}} & \multirow[t]{2}{*}{ 5d. PROJECT NUMBER } \\
\hline & & & & \\
\hline & & & & 5f. WORK UNIT NUMBER \\
\hline & & & & 984754.02 .07 .07 .18 .03 \\
\hline \multicolumn{4}{|c|}{$\begin{array}{l}\text { 7. PERFORMING ORGANIZATION NAME(S) AND ADDRESS(ES) } \\
\text { NASA Langley Research Center } \\
\text { Hampton, VA 23681-2199 }\end{array}$} & \begin{tabular}{l|l} 
8. PERFORMING ORGANIZATION \\
REPORT NUMBER
\end{tabular} \\
\hline \multirow{3}{*}{\multicolumn{4}{|c|}{$\begin{array}{l}\text { 9. SPONSORING/MONITORING AGENCY NAME(S) AND ADDRESS } \\
\text { National Aeronautics and Space Administration } \\
\text { Washington, DC 20546-0001 }\end{array}$}} & 10. SPONSOR/MONITOR'S ACRONYM(S) \\
\hline & & & & NASA \\
\hline & & & & \begin{tabular}{|l} 
11. SPONSOR/MONITOR'S REPORT \\
NUMBER(S) \\
NASA/TM-2010-216685
\end{tabular} \\
\hline \multicolumn{5}{|c|}{$\begin{array}{l}\text { 12. DISTRIBUTION/AVAILABILITY STATEMENT } \\
\text { Unclassified - Unlimited } \\
\text { Subject Category } 71 \\
\text { Availability: NASA CASI (443) 757-5802 }\end{array}$} \\
\hline \multicolumn{5}{|c|}{ 13. SUPPLEMENTARY NOTES } \\
\hline \multicolumn{5}{|c|}{ 14. ABSTRACT } \\
\hline \multicolumn{5}{|c|}{$\begin{array}{l}\text { Test subjects seated inside and outside a house were exposed to low-intensity N-wave sonic booms during a 3-week test period } \\
\text { in June } 2006 \text {. The house was instrumented to measure the booms both inside and out. F-18 aircraft were flown to achieve a } \\
\text { variety of boom overpressures from approximately. } 1 \text { to .6 psf. During four test days, seventy-seven test subjects heard the } \\
\text { booms while seated inside and outside the house. Using the Magnitude Estimation methodology and artificial reference } \\
\text { sounds, the subjects rated the annoyance of the booms. Since the same subjects heard similar booms both inside and outside } \\
\text { the house, comparative ratings of indoor and outdoor annoyance were obtained. For a given metric level, indoor subjects gave } \\
\text { higher annoyance scores than outdoor subjects. For a given boom, annoyance scores inside were on average the same as those } \\
\text { outside. In a post-test questionnaire, the majority of subjects rated the indoor booms as more annoying than the outdoor ones. } \\
\text { These results are discussed in this paper. }\end{array}$} \\
\hline \multicolumn{5}{|c|}{$\begin{array}{l}\text { 15. SUBJECT TERMS } \\
\text { Sonic boom; Human response; Annoyance; Noise; Supersonics }\end{array}$} \\
\hline \multicolumn{2}{|c|}{ 16. SECURITY CLASSIFICATION OF: } & 17. LIMITATION OF & 18. NUMBER & \multirow{2}{*}{$\begin{array}{l}\text { 19a. NAME OF RESPONSIBLE PERSON } \\
\text { STI Help Desk (email: help@sti.nasa.gov) }\end{array}$} \\
\hline a. REPORT & \begin{tabular}{|l|l|} 
b. ABSTRACT & c. THIS PAGE \\
\end{tabular} & & $\begin{array}{l}\text { OF } \\
\text { PAGES }\end{array}$ & \\
\hline & \begin{tabular}{l|l}
$\mathrm{U}$ & \\
\end{tabular} & & & $\begin{array}{l}\text { 19b. TELEPHONE NUMBER (Include area code) } \\
\text { (443) } 757-5802\end{array}$ \\
\hline
\end{tabular}

